\title{
ECONOMIC ASPECTS OF HUMAN CLONING AND REPROGENETICS
}

\author{
Gilles Saint-Paul ${ }^{1}$
}

\section{Université de Toulouse I and CEPR}

\section{INTRODUCTION}

The issue of human cloning brutally entered the public debate in 1997 when Dolly, a sheep, was created with a genotype identical to that of its mother by Scottish scientists who used somatic nuclear transfer ${ }^{2}$. Immediately, a debate on the ethical issues associated with the prospects of human cloning arose. As of today, human cloning seems closer than ever, since a scientist has claimed to have implanted cloned human embryos, scheduled for birth in December 2002.

This paper analyses the economic issues associated with human cloning and new reproductive technologies. We analyze the incentives for human cloning and its implications for the long run distribution of skills and income. We analyse models of human cloning for different motives, focusing on those which tend to produce new human beings with improved ability. We thus ignore purely therapeutic applications, which may well be the most likely ones to happen in the near future, but have no first-order implications for the long-run distribution of skills and income.

We first briefly describe the technology of cloning and its recent advances.

The second part of the paper discusses various economic incentives for cloning. It first analyses the consequences of cloning as a means of assisted reproduction. Next, we analyze the incentives to use cloning as a means of producing a high ability offspring in a couple where one member has a higher ability than the other.

Finally, in section 3.3 we discuss cloning as a form of financial investment. ${ }^{3}$ We argue that there will be strong economic incentives to clone people of exceptional value in the labor market. The extent to which the market will internalize this economic value depends, however, on how much of the return to the clone's genes can be appropriated by the agents who invested in creating the clone. We argue that the fraction that can be appropriated is likely to be small, but positive. If the clone's expected income is very large, this may be enough for cloning to be a profitable operation. A market for clones will then start operating, and we show that only the most talented people will be cloned, while women at the bottom of the ability distribution will specialize as physical mothers of the clones, thus getting a higher income than if working in the production sector.

An important consequence of these models is that if ability is genetically heritable, cloning tends to increase the proportion of high ability people in society, and that under some hypothesis the distribution of ability converges to a mass point at the highest possible ability

\footnotetext{
${ }^{1}$ This paper has been prepared for the Economic Policy panel meeting, Copenhagen, October 2002, and greatly elaborates on an earlier, theoretical paper entitled "The economics of human cloning". I thank seminar participants at IIES, Stockholm, DELTA, Paris, UCL, London, IDEI, Toulouse, the University of Chicago, and especially Jérôme Adda, Orazio Attanasio, Pierre Cahuc, Daniel Cohen, Kjetil Storesletten, Eric Posner, Richard Posner, Gary Becker, John Hassler, and the editors of Economic Policy Richard Baldwin and Paul Seabright for their helpful comments and suggestions.

${ }^{2}$ See Box 1 for a definition of technical terms.

3 This section, and the corresponding section in the Appendix, study a simplified version of the general equilibrium, overlapping generations model studied in Saint-Paul (2000). The main difference is that the marginal returns to labor and capital are held constant here, while in Saint-Paul (2000), they are endogenous and depend on capital accumulation. The reader can thus refer to Saint-Paul (2000) for a more complete analysis, and for additional results, in particular concerning the effect of cloning on factor prices and accumulation.
} 
level. Under weaker assumptions, it is shown that ability-reducing genes are eventually eliminated. However, if fertility is negatively correlated with ability, cloning leads to a strongly segregated society with a top-ability caste and a bottom ability one which produces clones of the top ability one.

Finally, Section 4 discusses the plausibility of these results in light on the evidence from economics and other sciences on marriage markets, child selection, assisted reproduction, and animals.

\section{A BRIEF HISTORY OF CLONING ${ }^{4}$}

Contrary to what many people would believe, the history of cloning does not start with Dolly. During the 1960's, that is even before the introduction of in-vitro fertilization (IVF), frogs were successfully cloned. The technique--called somatic nuclear transfer-- involves the creation of a fertilized egg or of an embryo with very few cells, and the replacement of its nucleus by a nucleus obtained from another cell. The embryo may then be implanted and its genotype is entirely that of the donor cell. In the case of oviparous animals such as frogs, the hazards associated with implantation are avoided, which explains why success was so quick. The 'younger' the donor cell, the more the resulting organism is likely to develop properly. Thus, cloning is more likely to succeed if the transferred nucleus comes from an undifferentiated cell coming from an embryo than from say an adult muscular cell. However, in the case of Dolly, the donor cell was a uterine adult cell.

The obstacles from the implementation of such a technique are thus purely technical, and it is not surprising that progress is being made at an astounding pace. Cows were cloned by French and Japanese scientists in July 1998. It quickly became a fairly reliable technique: 10 calves were cloned by scientists from New Zealand at the end of 1998. At about the same time, a large number of mice were cloned by researchers at the University of Hawaii. It is typically believed that mice were harder to clone than sheep, and that this represents a big step toward being able to clone humans. In early 2000, pigs were cloned, which was heralded as a progress towards the culture of spare organs for humans--due to the similarity in size between pigs' and humans' organs. It was envisioned that genetic engineering, by adding human genes on pig DNA material, could make such organs acceptable to human bodies. This was actually achieved in January 2002. In january 2001, an extinct species of wild ox, the gaur, was cloned; nuclei from skin cells of an animal who died in 1993 were removed and transplanted into cow embryonic cells. The gaur calf who was born died after 48 hours. In january 2002, a chip allowing to automate the process of somatic nuclear transfer was invented. This allows to mass produce cloned embryos, thus considerably reducing the cost of cloning, whose key impediment was the high failure rate. In February 2002, a domestic cat was cloned.

As for humans, there were reports of human embryo cloning as early as $1998 .{ }^{5}$ In december 01, a large number of rhesus monkey embryos were cloned. In march 02, dozens of human embryos were claimed to be cloned in China, while an Italian scientist reported successful implantation of cloned human embryos, scheduled for birth in December 2002.

How healthy are clones? Evidence from Dolly has suggested that clones may age prematurely, due to shorter chromosomes (chromosomes get shorter as people age. Hence a clone starts its life with a chromosome length equal to that of the original donor cell). However, cloned calfes have been shown to have longer chromosomes. The consequences of

\footnotetext{
${ }^{4}$ This section's source is the New Scientist web page press release archive, http://www.newscientist.com/ ; useful information can also be found in the BBC's "gene safari":

http://www.bbc.co.uk/science/genes/gene_safari/clone_zone/intro.shtml

5 "South Korean Scientists Say They Cloned a Human Cell", The New York Times, December 17, 1998.
} 
chromosome shortening on life expectancy are not well understood, and whether this feature explains why Dolly has prematurely developed arthritis remains unclear. Other DNA defects have been found in clones, and the failure rate remains quite high. It is unclear whether such defects could be avoided in the future.

On the legal front, most developed countries are moving towards a strict ban on human cloning, as far as the production of human beings is concerned. The stance is not as clear, and varies among countries, with respect to the therapeutic use of cloned embryos. The question, of course, is how can the ban be enforced and how long, given that some countries may well allow it, as suggested by the Chinese example.

\section{BOX 1: GLOSSARY ${ }^{6}$}

Adult cell: a fully differentiated cell of a body, specific to the organ in which it is present. Thus one may distiguish muscular cells, neurons, hepatic cells, blood cells, uterine cells, and so forth.

Artificial insemination: fertilization by means of artificial introduction of sperm in female reproductive organs instead of coitus.

Assisted reproduction: Refers to a set of treatments where infertility is overcome by using advanced technologies. These techniques include artificial insemination, IVF, traditional and gestational surrogacies, PGD, etc.

Chromosome: the microscopic, threadlike part of the cell that carries hereditary information in the form of genes. The chromosomes, which carry the hereditary material, or DNA, are contained in the nucleus of each cell. Chromosomes come in pairs, with one member of each pair inherited from each parent.

DNA: The chemical material from which chromosomes are made. 1 chromosome $=1$ single molecule of DNA. However, two chromosomes from different individuals are not the same molecule stricto sensu. Rather, they are a sequence of a large number of four building blocks called bases. These sequences differ across chromosomes and individuals. A gene is a "meaningful" subsequence, in that it synthesises a vital protein.

Gene: unit of hereditary information that occupies a fixed position (locus) on a chromosome. Genes achieve their effects by directing the synthesis of proteins. A given gene can come in several competing forms, called alleles. The resulting effect on phenotype (i.e. observed traits) of a given gene depends on the two alleles of that gene that are actually present in the two corresponding loci of a pair of chromosomes.

Genotype: the entire set of genes of a given individual.

Heterozygote: an organism with two different alleles for a specific trait. Contrary to homozygote.

\footnotetext{
${ }^{6}$ From http://www.infertility-info.org ; http://www.britannica.com; http://www.bbc.co.uk/science/genes/gene_safari/clone_zone/intro.shtml ; http://filebox.vt.edu/cals/cses/chagedor/glossary.html
} 
Homozygote: an organism with identical pairs of genes (or alleles) for a specific trait. If both of the two gametes (sex cells) that fuse during fertilization carry the same form of the gene for a specific trait, the organism is said to be homozygous for that trait.

Locus: a given location on a chromosome, where a gene (typically coming in several alleles) is usually present.

Nucleus: the central part of a cell, which contains DNA.

IVF: This acronym stands for "In Vitro Fertilization". Fertilising the egg in the laboratory for subsequent embryo transfer. Requires egg retrieval/pickup.

Oviparous: Refers to animals who lay eggs, such as birds, reptiles, etc. This contrasts to mammals.

Phenotype: the observable traits of an organism.

PGD: This acronym stands for "Preimplantation Genetic Diagnosis". It consists in screening an embryo for the presence of undesirable genes, prior to implanting it into a womb.

Recessive: a trait which is only present in the phenotype if the same allele is present in the two corresponding loci of the relevant chromosome pair. By extension one may talk about a 'recessive gene'.

Somatic nuclear transfer: this technique consists in producing a clone by first producing a fertilized egg via IVF, extracting the nucleus, which contains the DNA of the egg, and replacing it by DNA from an adult cell from the model. The fertilized egg is thus 'reprogrammed' to develop into a genetic copy of the model.

Stem cell: See undifferentiated cell.

Therapeutic Cloning: cloning a human embryo then used to produce replacement cells in order to provide a cure for the DNA donor. These includes blood cells, neurones, liver cells, etc. This procedure does not involve implantation of the embryo into a womb, nor its growth beyond a certain stage. In particular, the technique rests on the fact that a stem cell, if placed in an environment of differentiated cells, differentiates itself in the same way. Thus, one does not need to wait till the original embryo has differentiated.

Undifferentiated cell: at early stages of an embryo, its cell are undifferentiated, i.e. they are not specific to any organ. As the embryo grows, cells gradually 'specialize' into bone, muscle, neurones, blood, etc. However stem cells can be used as 'spare parts' in adult body, because of their ability to turn into any type of adult cell. See Therapeutic cloning.

Reproductive cloning: cloning a human embryo in order to implant it into a womb and let it develop into a human being.

Surrogate mother: a woman who bears a baby on behalf of another person, and who will renounce her rights as legal mother of the child. One distinguishes "traditional surrogates", who are artificially inseminated and therefore provide $50 \%$ of the genetic material, from 
"gestational surrogates", who are implanted an embryo following IVF and typically do not provide any of the genetic material.

\section{MODELS OF HUMAN CLONING}

\subsection{Assisted reproduction}

Along with therapeutic cloning, assisted reproduction is going to be the most likely motive for human cloning in the near future. ${ }^{7}$ In the current state of technology, assisted reproduction implies that $50 \%$ of the offspring's genes come from an egg or sperm donor who is unrelated to the legal parents. This may be unpalatable to the couple, and legal problems may pop out, as courts may rule that the donor is considered as the biological parent of the child, with corresponding obligations. Cloning gets out of this problem by allowing infertile couples to produce an offspring whose genes entirely come from one of their parents. ${ }^{8}$ Orentlicher (1999), for example, argues that cloning actually enhances the stability of families, as compared to existing means of assisted reproduction which introduce genes alien to the family into its offsprings. Many US lawyers argue that this is superior to the current techniques of assisted reproduction in preserving the cohesion of the family and avoiding legal complications.

There is not much economic analysis to be made about this motive. However, Posner and Posner (1998) suggest an intriguing possibility, namely that cloning by infertile people would eventually lead to the disappearance of sexual reproduction. The argument is simple: assume that everybody makes the same number of children and that $2 \%$ of the offsprings are infertile for genetic reasons. Absent cloning, the proportion of infertile people in the population is fixed at $2 \%$. Now, let us assume that cloning is available and that the infertile produce the same number of children as others but by cloning themselves. By definition, their clones are infertile too. But at each generation, to the infertile clones one should add the infertile natural offsprings of fertile couples. So the proportion of infertiles goes up at each generation and the economy converges to a situation where everybody is infertile and sexual reproduction has therefore disappeared.

In order for this argument to be correct, it must be that infertility is caused by some mutation. Under sexual reproduction, the infertility of mutant genes tends to eliminate them, thus preventing their proportion to go beyond $2 \%$. Under cloning, mutant genes proliferate, since they are passed to the next generation by cloning. This could be offset by a reverse mutation which would restore fertility to an infertile genotype, but such event is precisely not possible since the offsprings of infertile people are their clones!

Or is it? Some geneticists (Silver, 2000) envisage a world where reprogenetics technologies are much more sophisticated than somatic nuclear transfer. They envisage a world where specific genes could be removed or added at specific loci. In such a world, infertile people would not clone themselves, they would rather engineer a fertile offspring by removing the genes responsible for their infertility from an initial embryo, who could be a clone of themselves, but would only be an input in the production of a genetically enhanced

\footnotetext{
${ }^{7}$ It is typically envisioned that if cloning is ever permitted for reproductive reasons, it will be limited to infertile couples (See Robertson (1999)). However, I do not see how this is compatible with equal rights; furthermore enforcing such a distinction might not be obvious.

8 See Robertson (1998).
} 
child. In such an advanced world, infertility would disappear, rather than drive out fertility, and so would cloning for the purpose of assisted reproduction. ${ }^{9}$

Another situation in which the Posner and Posner result would not apply is if infertility, rather than being caused by mutation, were produced by a rare recessive gene. In such a case, absent cloning the recessive gene would gradually be eliminated from the population. Under cloning, it would be maintained in its initial proportion, and one can also show that heterozygotes would disappear. This is because heterozygotes sometimes produce infertile homozygotes, who will only pass their genes via cloning, thus never producing heterozygotes in the future.

\subsection{Child enhancement: Parental cloning ${ }^{10}$}

Once human cloning is established as an additional technique of assisted reproduction for infertile couples, it would be discriminatory (and probably unenforcible) to preclude fertile couples from using it as well. An additional demand for cloning coming from fertile couples is then likely to arise. If people care about their children's human capital, they may want to have clones of high ability people as children. We do not expect many couples to be willing to raise children who are clones of other people, i.e. genetically unrelated to either mate. However, within a couple there may be an incentive to raise a clone of the most able's member rather than a natural child; or, to have some naturally produced children along with one or several clones of the most able party.

When will a couple decide to produce a clone? Let us assume that the decision to produce a clone vs. natural children is the outcome of bargaining between the two parties. In order to figure out what this bargaining process will deliver, let us make the following natural assumptions:

1. A person's utility is higher if the child is genetically related than if he is not. However, it need not be increasing in the number of shared genes. Thus we do not rule out that people love their sexually produced children more than their clones. But they do love both more than their spouse's clone.

2. A person's utility is higher, the greater the skill of his/her offspring.

3. The clone has the same ability as its model.

4. The naturally produced offspring has an ability equal to the average of its two parents. ${ }^{11} 12$

We assume that the couple maximizes its joint surplus, i.e. the sum of the mother's and the father's utilities. It is then not difficult to establish a certain number of properties.

\footnotetext{
${ }^{9}$ Unless some people produce infertile children on purpose.

${ }^{10} \mathrm{~A}$ formal analysis of the models of parental and economic cloning is found in the Appendix.

${ }^{11} \mathrm{We}$ just have to assume that its expected value is equal to this average; it may vary randomly.

12 One special case of this set of assumptions is the "sociobiological view", which relates the degree of altruism to the number of shared genes. Under such a view, a dollar of consumption of one's clone is worth the same as a dollar of own consumption; a dollar of consumption by a sexually produced offspring is worth half a dollar of own consumption; and a dollar of consumption by a spouse's clone is worth nothing.
} 
First, cloning is more likely to take place, the more ill-assorted is the couple. ${ }^{13}$ In such a case the total value to the couple of cloning the most able party is greater than that of making a sexually produced child who is expected to have a much lower ability. The least able party may either gain or lose from such cloning but if it loses, then it loses less than what the most able party gains.

One consequence is that cloning is less likely to prevail, the more mating is assortative, i.e. the more people find mates with similar characteristics.

Second, if cloning arises then it will affect the long-run distribution of abilities in society. High ability people are going to be produced more frequently than in a no-cloning society. Let us assume that if only sexual reproduction prevailed, then the distribution of abilities among offsprings would be the same as among parents. We call this assumption the ability invariance hypothesis. It is actually true at the level of the gene if fertility is uncorrelated with ability. To keep things simple we go one step further and actually assume it is true at the level of ability. Then, absent cloning, the distribution of abilities among the population would be stationary, i.e. it would reproduce itself indefinitely. How does cloning modify this situation? Some couples will replicate the most able party rather than producing a child whose expected ability is the average of the two parties. Therefore, cloning produces a deformation of the offsprings' ability distribution which takes weight out of the low end and adds weight at the high end. Now, this deformation will be passed on to future generations through sexual reproduction, since it leaves the distribution of abilities unchanged. And future cloning will add further deformations in favour of high-ability workers. As this process continues, the highest ability type crowds out all the others. Hence:

Under the Ability Invariance assumption, society converges to a perfectly egalitarian world with only people of the highest ability type.

It is important to note that even a tiny amount of cloning is enough to gradually eliminate low ability types from the population and to make sure that the distribution of ability converges to a mass at the highest ability type. Simply, if fewer people clone themselves, this convergence process is slower.

The ability invariance assumption is a strong one. More fundamentally, we expect the distribution of genes to be preserved in sexual reproduction, provided birth rates are constant across types or uncorrelated with genotypes--The Gene Invariance assumption. The above result is then no longer valid in general if gene invariance holds but not ability invariance. However, one can show that if there exists a gene such that all people who have it are of the top ability type, then convergence to the egalitarian society where all agents are of top ability holds again. This is because the frequency of the high ability gene is bound to increase at each generation, as top ability types are those who produce the greatest number of clones, and gene frequency is preserved among sexually produced offsprings.

Some other weaker results can be established under gene invariance, we will discuss them below in the context of the analysis of economic cloning.

Finally, let us mention that cloning is also likely to affect the pattern of mating and sexual reproduction. The option of cloning oneself reduces the cost for high ability people of turning down low ability mates, so one may see a decrease in the degree of assortative mating.

\subsection{Cloning as an investment: Economic cloning}

\footnotetext{
${ }^{13}$ Note that it is never worth cloning the least able party.
} 
We now discuss a possibility which is more remote, namely cloning for economic reasons. If top performers in the labor market have valuable genes, then cloning them will generate a lot of economic value. The question we first ask is: can the market develop incentives for such cloning to actually take place $?^{14}$ A key issue is how much of the clone's income can be appropriated by those who invested in creating it.

\subsubsection{The role of property rights}

If a clone were treated as a product, it could be patented. Those who put up the resources needed to produce the clone could then reap all the returns to the clone's genes by forcing "it" in the highest return occupation and expropriating all its labor income. In this case, the market would internalize the "social benefits" of cloning and produce a large number of copies of Bill Gates and of various top physicians and lawyers. Moral hazard could mitigate these effects, but the producers could still get considerable returns on their investment by imposing an adequate incentive contract.

However, clones are human beings, and, in Western countries, are likely to be granted the same civil rights as other individuals ${ }^{15}$. People cannot be patented. If they do not have to abide by a contract they have not signed, they will appropriate all the returns to their genes, and the private economic incentives for cloning will be non existent.

This brings the following question: in a free, democratic society, what sort of devices could investors use to appropriate part of the labor income of an individual they have produced? Let us suggest the following appropriability mechanisms.

The simplest one is a negative bequest. The clone could be legally adopted by its model and the model would borrow money that would implicitly be backed by the clone's future earnings. Such negative bequests are illegal in most western countries, but not in Japan, for example. Negative bequests come close to full appropriability of the clone's income.

Another possibility is information retention. A cloning firm could buy some DNA from a top ability individual and produce clones in the hope of selling them valuable information about their model: genealogy, career, etc. This information would also be verifiable by any potential employer. Upon being contacted by the firm, the individual would learn that he or she is the clone of a top ability worker. He is then willing to pay a substantial amount of money to know whether he is the clone of a violinist or a surgeon. Thus, by withholding information about the model's specific talent, the firm is able to appropriate part of the clone's labor income. ${ }^{16}$

An extreme form of information retention is genome ownership. There is now a debate about whether genetic code could be patented. If this turns out to be legal, the firm could simply own property rights over the model's genome and its clones could have the option to buy it, so as to use it in order to improve their health and labor market prospects. In the former case, their motivation for buying their genome is unrelated to their earnings ability; nevertheless, their willingness to pay for it is likely to be greater, the greater their earnings. Hence the incentive to clone top performers remains. By making clones, the firm would then

\footnotetext{
${ }^{14}$ At this stage, an important caveat is in order: we are not advocating that society should seek to establish property rights on cloned human beings, albeit indirectly. We are just examining different mechanisms allowing to appropriate part of the clone's income. The more efficient these mechanisms, the more likely it is that a market for cloning will arise. We are not claiming that these mechanisms should be enhanced, nor that they will necessarily be strong enough for cloning to arise.

${ }^{15}$ The National Bioethics Advisory Commission (1997) advocates that "any children born as a result of this technique should be treated as having the same rights and moral status as any other human being"

${ }^{16}$ Note that in such a case appropriability need not reduce the clone's welfare relative to the model's welfare, since the clones saves on the costs of learning his best skill.
} 
simply generate customers for a given genome. Or, more horrendously ${ }^{17}$ but perhaps more realistically, one could on purpose clone top ability people affected by a genetic disease requiring an expensive treatment, in order to sell the treatment to these clones--a genetic form of 'advertisement'. ${ }^{18}$

Finally, one could potentially extract rents from clones via their specificity. If the clone's specific talent is complementary to some form of capital, and if the owner of such capital may bar competitors from accumulating/acquiring it, then they can expect to be in a situation of monopsony, or bilateral monopoly, vis-à-vis the clone, which will allow them to extract part of the return to the clone's talent.

For example, the movie industry had considerable difficulties in finding a replacement to Sean Connery, the actor who played James Bond. The economic value of Connery's specific physical characteristics is huge, and an obvious solution is to clone him. Under perfect competition in the movie industry, this will not be of any help, as Connery's clone would get all the returns; but under imperfect competition, potential profits are large compared to the cost of making the clone. ${ }^{19}$

This example is of limited relevance, though, because only one copy of Sean Connery is needed (although one could make several for the purpose of having them compete with each other). ${ }^{20}$

However, a similar mechanism could arise through higher education. The returns to higher education are higher for top ability people. But there aren't that many top schools, so that competition among those schools is imperfect. As a result they are able to extract rents from their students in the form of tuition fees and gifts. They expect to get greater rents from more able students. Hence, a consortium of top schools could invest in the cloning of top individuals, knowing that a fair fraction of these clones will get educated at a top school. This mechanism is operative only to the extent that there is no free entry in the market for education. Otherwise, competitors would free-ride on the top universities institutions' cloning investment by offering better terms and the consortium would eventually run out of business, as it is unable to recoup its investment.

Clearly these mechanisms will generate an equilibrium level of cloning much lower than if clones were granted fewer rights than original human beings. However, it is not unreasonable to speculate that if the income prospects of the individual are large enough, there will be enough incentives for cloning him or her even at such low appropriability levels. $^{21}$

\footnotetext{
17 Such a mechanism is not so different from the one currently in use, which consists in artificially making a good addictive in order to increase demand and/or demand elasticity. For example, there are testimonies about the cigarette industry's alleged practice of adding nicotine to cigarettes. See US FDA (1994), at http://www.fda.gov/bbs/topics/SPEECH/SPE00052.htm

18 Indeed, property rights on genetic information are evolving and there already exists a market for it. For example, Incyte, Inc. is a firm specialized in maintaining and selling a database of DNA information, that it sells to pharmaceutical firms. (Source: http://www.accessexcellence.org/AB/BA/genomics/genomic1.html ) Clearly for such a firm to survive in the future, property rights on DNA information must be enforced. According to the New Scientist, 15/12/2001, Oxford GlycoSciences, a British company, had filed for patents on 4000 human proteins and the genes that code for them. These are all proteins linked with illness. Oxford Ancestors Inc. is a company which sells DNA tests to people in order to find genetic markers relating them to one of seven primitive "mothers" who lived 150,000 years ago.

19 Another potential example could be the tabloid's press incentives to make a clone of Princess Diana. Again, this mechanism is operative only to the extent that the rents it generates are not fully dissipated by entry in the tabloid sector.

${ }^{20}$ This is because the media are themselves a cheap replication technique, indeed cheaper than cloning, so that only one copy of Sean Connery or Princess Diana is needed for its purpose.

${ }_{21}$ Contractibility problems associated with the surrogate mother, on the other hand, are lighter, and not much different from those already existing in the context of assisted reproduction. The firm could make sure the clone
} 
To conclude this section, let us point out that, just like cloning need not be banned in all countries, some countries may develop a legal system where clones have fewer rights. Clearly, different cultures have different views about say, the rights of women or children, so they might also treat clones differently. If this is so, appropriability may be high in a subset of countries. Even if these countries are small, by attracting foreign direct investment in cloning they may contribute to a high level of cloning worldwide.

\subsubsection{Determinants of the market for clones}

Let us now take for granted that some appropriability is feasible, and analyze how the equilibrium level of cloning would be determined.

We assume that people can invest money in creating a clone of themselves. We rule out any 'narcissist' or 'megalomaniac' motive for cloning; people are not made happy by the existence of a copy of themselves. But when the clone becomes an adult, the model is able to extract a fraction of his/her earnings. We denote by $f$ that fraction. The cost of producing a clone is $p$, and we shall assume for simplicity that it is entirely made of the compensation to the surrogate mother (including child raising costs). Finally, people differ in their ability, which is denoted by $a$. The present discounted value of their earnings is given by $a . w$, i.e. it is proportional to ability. ${ }^{22}$ Clones have exactly the same ability as their model.

When is it profitable to clone oneself? Clearly, when it yields a return which is at least larger than alternative investments. This will be true if

faw $>=p(1+r)$

where $(1+r)$ is the return to alternative investments. The left hand side is the total value of the money extracted from the clone. The right hand side is how much one would have made by investing in other assets.

Consider an individual for whom this inequality is strictly satisfied. How many times will he/she want to clone him/herself? The answer is: an infinite number of times. This is because he can give away his DNA as many times as he wants. DNA is just a blueprint, a piece of information, which is replicated very many times in each of the huge number of cells that we have. From the point of view of the cloned individual, there is no scarcity constraint associated with the factor he/she is contributing to the clone.

Consequently, this inequality cannot hold strictly, implying it must be violated for all agents except the highest ability type. If cloning takes place then it must be satisfied with equality for that type, implying that the price of a clone must be equal to $p=p^{*}=f a^{*} w /(1+r)$, where $a^{*}$ is the maximum ability level. Consequently, only the highest ability agents will be cloned. Because, for a given $p$, there is no limit to the replication of a given individual, and because the gains from cloning oneself are increasing with ability (since one knows for sure

develops properly by having her sign a contract specifying her diet during pregnancy, etc. One should note, however, that once the clone exists there will be a situation of bilateral monopoly between the surrogate mother and the firm. Such problems already arise regarding existing techniques of assisted reproduction. See Posner (1989). According to Chester (1997), Dr. Joseph Schulman, the director of the Genetics and IVF Institute, advocated in June 1997 that such problems should be solved by writing a "complete" contract between the parties involved. Chester claims that there is a legal vacuum surrounding these issues and that such contracts should be regulated for equity reasons, given the unequal bargaining power of parents, surrogates, and fertility clinics. He also reports a New Jersey case of a conflict between a (genetic) surrogate mother and the inseminator's household, where the surrogacy contract was invalidated but custody was granted to the latter.

${ }^{22}$ For simplicity we assume constant factor prices, or equivalently a linear production function given by $Y=w L+r K$. For a detailed general equilibrium analysis based on an overlapping generations model, see SaintPaul (2000). 
that the clone will have the same ability as the original), the most able agents bid up the price of cloning until less able people are driven out the market. ${ }^{23}$

In other words, the demand for cloning is infinitely elastic. In particular, it does not depend on the number of people at the highest ability level. This is because they can supply an arbitrarily large amount of their DNA at zero marginal cost. One could even assume that a large fraction of the population does not want to clone itself. It is enough that some individuals at the highest ability level are willing to do so to boost the price to $p^{*}$. The number of clones that will be produced does not depend on demand, but on supply. A reduction in the number of high-ability workers willing to be cloned will simply be offset by an increase in the number of times each of them is cloned.

Therefore, let us now look at the supply of clones. We assume that to raise one clone, one needs a surrogate mother who must sacrifice a fraction $b$ of her income per clone. ${ }^{24}$ An individual with ability $a$ will become a surrogate provided the time spent raising a clone yields more money than if it were devoted to work. This is true provided the compensation per clone satisfies the following inequality:

$p>=b a w$.

Consequently, an individual with ability $a$ becomes a surrogate if and only if her ability is lower than a critical level given by

$$
\tilde{a}=p /(b w)
$$

Low ability agents have a comparative advantage in producing clones. This threshold increases with the price of clones and falls with the opportunity cost of producing children $b w$. Cloning does arise in equilibrium if there exists a positive mass of agents with ability below the threshold level $\tilde{a}$. Let $\underline{a}$ be the lowest possible ability level. Using the formula for the equilibrium price $p^{*}$, we see that cloning will arise if

$\underline{a} / a^{*}<f /(b(1+r))$.

This condition is more likely to hold,

- the lower the time cost of producing children, $b$.

- the higher the appropriability of clone income $f$.

- the lower the rate of return $r$.

- the lower the ratio between the lowest and highest ability level.

The last property tells us that cloning is more likely to arise in more unequal societies. Cloning is more likely to arise, the lower the opportunity cost of time of those who produce clones relative to the income of those who get cloned, i.e. the greater inequality.

\footnotetext{
23 This phenomenon would be mitigated if there were no perfect substitutability across ability types, in which case the amount of cloning in each type would be determined so as to equate incomes across clones. See section 3.3.4.2.

24 The idea that people would not accept to serve as surrogate mothers was already dismissed in Watson's (1971) visionary article, which was written some years after a frog had been successfully cloned, but prior to the first successful in vitro fecundation. He writes "There already are such widespread divergences regarding the sacredness of the act of human reproduction that the boring meaninglessness of the lives of many women would be sufficient cause for their willingness to participate in such experimentation (...)"
} 
Cloning is also more likely, the lower the real interest rate, because it is an alternative form of financial investment. Finally, the first two properties are straightforward: cloning is less likely to arise, the greater its cost and the smaller the fraction of the clone's income that can be appropriated.

Hence, society will organize itself in three classes: a reproductive class at the bottom of the distribution of ability; a productive class at intermediate levels; and a replicated class at the very top of the ability distribution.

\subsubsection{Long-run consequences}

In the case of parental cloning discussed above, we have seen that the distribution of abilities converges towards a mass of top-ability workers, provided the Ability Invariance assumption holds. Economic cloning has the same implication, and the effect is much stronger. In the case of parental cloning, cloning generates a gradual deformation of the distribution of abilities in favour of high ability types. In the case of economic cloning, the deformation is in favour of top ability types. Thus the speed at which the distribution of ability is equalized and driven to the top is much higher.

Another important consequence is that cloning eventually vanishes in the long-run. The reason is that society falls short of low ability people willing to act as surrogate, as top ability people make up for an increasing fraction of the workforce.

These results depend a lot on the Ability Invariance assumption, which implies that sexual reproduction among top-ability agents only yields top-ability offsprings. This long-run equilibrium could not be sustained if sexual reproduction introduced some noise in the distribution of offsprings' abilities. That is, under the ability invariance hypothesis the ability distribution drifts under the pressure of transitory events without any tendency to return to some stable long-run steady state. Therefore, even a vanishing amount of cloning is enough to transform it permanently into a perfectly egalitarian distribution.

Under the weaker gene invariance assumption, mating between high ability people may produce some low ability people, and this process may prevent the fraction of people below a certain ability level from vanishing in the long run. Hence the preceding results no longer hold: low ability people may still be produced by mating among high ability ones, which prevents income equalization and may maintain a strictly positive relative supply of surrogates. However, a weaker result can be established, which is as follows.

Suppose there exist genes which prevent ability from being greater than a certain level. In particular, suppose that initially there is a strictly positive fraction of genes which prevent ability from being greater than $\tilde{a}$, the critical ability threshold. This implies that at each generation we will find a strictly positive number of people willing to act as surrogates, so that some cloning will take place. Then it can be shown that the frequency of genes which prevent ability from being maximum--let us call them $l$-genes--eventually goes to zero. The logic is simple: cloning implies that the genes of top ability people are replicated at a higher rate than other genes. Given that $l$-genes are never found in top ability people, they eventually vanish.

This does not imply that all people are of top ability in the long run; nor is it true that cloning vanishes. $l$-genes, and, in particular, genes which reduce ability are eliminated. But, in the long run, other genes can be combined to produce ability levels below the top, which may even, in principle, be low enough to maintain the supply of cloning.

\subsubsection{Extensions}


The preceding model provides a useful benchmark but ignores several aspects which we now discuss.

\subsubsection{Other demographic dynamics}

It is useful to consider two other departures from the ability invariance assumption:

1. Mutation: Mutation implies that a fraction of sexually produced offsprings will have new genes not found in their parents. Thus ability invariance is no longer satisfied. If some low ability mutants are produced at each generation, society no longer converges to full equality. Furthermore, these mutants may prevent the relative supply of surrogates from going to zero, so that cloning need not vanish in the long run.

2. Negative ability dependence: One may also plausibly assume that fertility and ability are negatively related. ${ }^{25}$ For example, in the U.S. 1995 census, the birth rate was 91 per 1000 for women with a family income lower than $10,000 \$, 60$ per 1000 for the 30,000-35000 \$ income range, and 53 per 1000 for a family income greater than $75,000 .{ }^{26}$ With fertility correlated with ability, the ability invariance property collapses, as does the gene invariance one. Absent cloning, the long-run distribution of income would collapse to a mass point at the most fertile group, i.e. the lowest ability level. When cloning is available, the top ability group is able to maintain its relative size through cloning. Indeed, the growth of the low ability group increases the 'supply' for clones proportionately, and even a single high-ability individual would be enough to produce a large mass of clones. As a result, instead of converging to a fully egalitarian society with only the lowest ability level, the distribution of income converges to two mass points, one at the lowest ability level, the other at the highest one. Top ability people make fewer children than anybody else but their size is artificially maintained by cloning. In the long run, a two-class society emerges, with low ability people producing the clones of top ability ones, while people at intermediate ability levels have vanished, as they make fewer natural children than bottom ability types, and are not cloned either.

\subsubsection{Non homogeneous labor input}

In the above analysis, there is a single homogeneous labor input, i.e. ability is unidimensional.

What would happen if ability were multidimensional? Assume for example that people belong to different occupations, which are complementary in the production process, and that within each occupation they have different skills. Assume that both 'talent', i.e. which occupation one is best at, as well as ability is heritable.

Then one can show that the results are not much affected. If anything, the scope for cloning is enhanced, because heterogeneity of occupations introduces an additional source of variance in the distribution of income. The poorest in the least scarce occupation earn less than if there were only one occupation, while the richest in the most scarce occupation earn more.

The only novelty is that cloning is gradually diffused from the scarcest to the most common occupation, while it remains true that within each occupation only the most able are cloned. The most able individuals in the scarcest occupation are cloned first. This increases

\footnotetext{
${ }^{25}$ From a methodological point of view, however, this is somewhat unsatisfactory, because it means that the initial distribution does not correspond to a long-run steady state.

${ }^{26}$ See U.S. Census Bureau (1997), table A.
} 
the relative supply of labor in that occupation, thus taking care of its "scarcity". This process continues until the point where there exists another, equally profitable occupation. Top individuals in both occupations are then cloned, and so on. During this process, at any date there exists a set of best-paying occupations whose top performers are cloned. Because of complementarities, cloning brings down the relative wage of these occupations relative to others, so that the set of best-paying occupations widens with time. Asymptotically, each occupation pays the same wage. Then cloning proceeds so as to maintain that same wage equal across occupations, by increasing labor supply proportionally in all sectors. Asymptotically, people are again all of the top ability type but have different occupations.

In principle, the market should eventually work well in identifying the occupations where cloning is most valuable. However, in early stages this might be more difficult. In particular, replication of the most able individuals may have very different effects depending on the nature of the good being produced and on the structure of the corresponding market.

For instance, there will be greater incentives to clone workers whose skills are not replicable by other means. For example, the books written by a top economist are replicable at low cost, and this will reduce the value of cloning the economist; the skills of a surgeon are much harder to replicate. In other words, there is some substitutability between biotechnology and information technology. In fact, cloning is just another new information technology applied to life. The DNA is a sequence of bits and cloning is no different from copying a computer programme.

In such an example, the surgeons rather than the economist will be cloned. On the other hand, the clones of the top economist, while being economists themselves, may end up writing totally different books. ${ }^{27}$ Their brains, while having the same efficiency and hereditary predisposition for economic analysis, will be 'wired' differently, as the result of a completely different experience. Assuming that the top economist earns much more than the top surgeon - precisely because IT allows him/her to cover a much larger market - then one would reach the opposite conclusion that the top economist should be cloned first. This is what the market would do by just looking at their wages, whereas in the case where the economist's clones would (unexpectedly) write the same book, the market would inefficiently clone them.

More generally, there exist professions where value is created not out of a huge direct or indirect productivity (like managers), but out of creativity, which is greater, the more different their output is relative to the existing stock of goods. Whether it is worth or not to clone them depends on how the nature of their creations depends on their genes vs. their acquired experience, a topic on which little is known and beyond the scope of this paper.

A related issue is the extent to which competition between clones of the same individual could exert negative effects on their earnings. If this is simply due to the fact that they exert the same occupation, this is well taken into account by the above analysis: the market will create just the right number of clones of top ability workers in a given ability dimension, so as to make sure that top ability people have the same earnings in any occupation. Thus if an occupation initially earns more than others, more cloning will take place, which will indeed depress earnings in that occupation, but not to the point of making cloning initially unprofitable. However, there is also the case of "winner-takes-all" markets where individuals are competing for a fixed prize: sports, and perhaps stock broking. In such a case, cloning does not create any value. By increasing the number of top contenders, it just reduces the probability that a given individual gets the prize - a pure congestion externality. It does not follow that cloning would not take place, as cloners don't internalize that externality. But the expected reward is inversely proportional to the number of top contenders, so we expect very few clones to be made in such labor markets, relative to ordinary labor

\footnotetext{
${ }^{27} \mathrm{I}$ am indebted to an anonymous referee for this point.
} 
markets. Finally, note that the actual quantitative relevance of such winner-takes-all situations is a matter of debate.

\subsubsection{Environmental shocks}

An important assumption made so far is that the ranking of workers by ability is invariant over time. More realistically, one could assume that some changes in the environment overturn that ranking. Thus, low ability people could become high ability, and vice-versa. A clear example in nature is how the fitness advantage of skin color is related to climate: bears are white in cold climates, and brown in warm climates. A climate change can thus overturn the fitness ranking of skin color.

It is not so clear whether such a reversal can take place with respect to earnings ability: it may be that greater ability means greater adaptability too. Let us however assume that environmental shocks can change the ranking of genotypes in terms of earnings ability. Then one has to distinguish two cases.

If any genotype has an equal probability of having its ability go up or down, as a result of an environmental shock, then the change in the ranking is not predictable, and the ranking of expected abilities is the same as the current one. ${ }^{28}$ In such a situation, the highest ability type today is the best bet one can make for the highest ability type in the future. Environmental shocks make investment in cloning more risky, but if cloning takes place one will still clone top ability people. As for the risk itself, whether it increases or reduces the incentives to clone depend on the correlation between the cloning risk and aggregate consumption. If people are risk neutral or if this correlation is zero, then the incentives for cloning are unchanged.

If it is known that future environmental shocks will overturn the current ranking of abilities, or reshuffle it in such a way that the most able people in the current environment have no greater chance to be among the most able in the future environment, ${ }^{29}$ then the distribution of abilities in terms of average lifetime ability is much more compressed than the distribution of current abilities, and this effect typically reduces the incentive for cloning.

\section{OBJECTIONS AND EVIDENCE}

The preceding analysis does not attempt to describe the future, and even less to advocate cloning. It merely analyzes the economic forces behind human cloning, and suggests that cloning - either for economic reasons or for child enhancement purposes -, if it takes place, will increase the proportion of high ability genes, and possibly lead to equalization of income levels from the top.

Clearly, there is enough uncertainty about the evolution of scientific knowledge, reproductive technologies, of the legal environment and of relative prices, that one may doubt whether this will happen at all. A number of objections can be raised; we now discuss them in light of the available empirical evidence.

\footnotetext{
${ }^{28}$ This would be the case if upon a shock the new ability level associated with a given genotype has a martingale property, i.e. in expectations it is equal to its previous value.

${ }^{29}$ This would be the case, for example, if upon an environmental shock, the new ability level associated with a phenotype were drawn from a distribution independent of the initial ability distribution.
} 


\section{Objection \#1: People don't marry and make children for utilitarian/monetary} purposes.

Different people marry for different reasons, but it is well-known that love is the main motive for marriage only in certain civilisations, time periods and social classes. There is evidence that mate selection on the basis of physical and economic characteristics is pervasive. Love itself can be interpreted as a biochemical trick, a legacy of natural selection which induces us to maximize the survival value of our genes.

Note that the value of a mate is twofold, as it affects the quality of children and the utility derived from the match. A high ability spouse may be selected because of his/her effects on offspring or because of the sheer impact on the value of the match. It is often hard to disentangle these two effects.

Selection of mate on the basis of economic and physical characteristics is evident from the empirical literature on the economics of marriage.

Murray (2000) shows that married men live longer and that this is partly due to selection. Harper (2000) finds that physical appearance affects the likelihood of getting married. Nakosteen and Zimmer (1997) show that part of the observed wage premium to married men can be ascribed to a higher probability of getting married for men with greater earnings. Along the same lines, Cameron and Collins (1999), who study female personal advertisements, find a positive correlation between the likelihood of an ad insisting on a potential repondent's physical appearance and that of the female offering wealth.

Marriage in polygynous societies is typically associated with a transfer from the husband to the wife's relatives. As a result, wealthier males have more wives. ${ }^{30}$ If wealth is correlated with genetically determined ability, then a polygynous society bears some resemblance to the cloning society we discuss in this paper. The most able males have more offsprings. Their wifes play to some extent the same role as surrogate mothers in cloning markets. One key difference, however, is that in a cloning market top ability females will also be able to reproduce at a supranormal rate, which is not the case in a traditional polygamous society, or indeed in any population where only sexual reproduction prevails.

Borgerhoff-Mulder $(1995,1998)$ has studied the determinants of bridewealth transfers in the Kipsigis, a traditional East African society. Her findings suggest that marriage is very much an economic investment, and that bridewealth--the "price" of a woman-- reflects the return to that investment relative to other alternatives. Thus, bridewealth falls when the relative supply of women goes up. Similarly, a woman's value also rises with her agricultural productivity. This is true both for aggregate determinants of productivity -- hence the sharp rise in bridewealth observed during the colonial era, which was associated with the introduction of cash and induced productivity gains from specialization -- and for individual ones. It is also plausible that part of the value reflects the expected quality and quantity of children. Indeed, Borgerhoff-Mulder argues that a recent fall in bridewealth is partly due to a fall in planned family size. Another factor is the rise in alternative forms of investment, such as equipment.

Bridewealth is higher for brides from wealthy elite families, which probably reflects the value of useful social connections rather than genes. It is higher for brides who reach menarche early, thus reflecting their greater reproductive value. ${ }^{31}$ Interestingly, it is also

\footnotetext{
${ }^{30}$ See Bergstrom (1996) for a survey and Bergstrom (1994) for a theoretical model.

31 But this correlation has disappeared in recent years, in accordance with the hypothesis of reduced planned family size. Bridewealth is also found to be lower for women who already had children from another man, and also for women who are pregnant from the groom. In the latter case, this is paradoxical, since it is a proof of fertility. However, Borgerhoff Mulder argues that in such a case, the bride's family bargaining power is very low.
} 
increasing with the distance between the bride's home and the groom's home. According to Borgerhoff-Mulder, this is because women from a nearby household are likely to spend more time with their mother, which reduces their productivity. We find it equally plausible that distance increases reproductive value by reducing risks of consanguinity. ${ }^{32}$ It is also found that wealthy grooms pay more for their wifes. This may reflect monopoly power or some unobserved desirable bride characteristic, which wealthy men are more likely to afford. Finally, bridewealth is higher for women with secondary education, reflecting higher productivity or higher child quality, for nurturing or genetic reasons.

In contrast, the literature has found that children were not a profitable investment from a pure economic viewpoint. The present discounted value of child food intake in traditional societies is larger than the PDV of their agricultural output. ${ }^{33}$ However, this does not rule out a role for economic motives. The desire for children is balanced by the economic costs, and this cost is lower, the greater the children's contribution to household income. ${ }^{34}$

\section{Objection \#2: People do not want to select their children's characteristics.}

Another objection to parental cloning is that people will prefer to let nature operate rather than choose their children's characteristics. There are reasons to have doubts about this objection.

The market for adoption gives evidence of how parents can select the characteristics of their children when left free to do so. In the case of adoption, price variation across children typically take the form of adoption delays, especially since U.S. law prevents birth mothers from being paid compensation. Thus, adoptionservices.org, an adoption agency, makes the following statement: "In general, healthy Caucasian newborns and infants are the most sought after children and the wait for these children can be many months to many years. If you are willing/desirous of adopting a Black, bi-racial, or multi racial child, the wait may be much shorter - only a matter of a few months. A special needs child, e.g. an older child, or a child with physical, emotional, or intellectual limitations, can often be adopted through special county, state, or private agencies in a relatively short period of time. The waiting period for foreign-born children usually depends on the specific foreign country the child is adopted from and can vary from a few months to a few years." Monetary costs vary in the same direction as delays: "You'll usually find that the costs involved in adopting a healthy Caucasian newborn/infant are higher than in adopting a child of other races, children with special needs, or children from other countries." (However, the prices quoted by that same agency only vary with geographical origins: 19-22,000 for Chinese children, 23-27,000 for Eastern Europeans, and 34-35,000 for US born, regardless of race).

Technology is now proceeding at a very fast pace in order to provide parents with options to select their children's genetic characteristics. This may obey several motivations: avoiding health problems, selecting a child's sex as the result of social pressure and/or other factors (such as diversification), attempting to have good-looking and healthy children.

Embryo screening, also known as pre-implantation genetic diagnosis (PGD) is developing very quickly and may be used to eliminate embryos with genes that favour diseases such as Downs syndrome, Cystic Fibrosis, or Huntington's disease. More recently one can detect genes for low IQs, dwarfness, obesity, and obviously observe the sex of one's

\footnotetext{
${ }^{32}$ But such a sophisticated justification need not pop out in interviews.

${ }^{33}$ See again Bergstrom (1996).

${ }^{34}$ There also exists evidence that parents invest more in their biological than non biological children: See Case et al. (2000).
} 
child. Psychological problems such as panic and manic depressive illness have recently been found to be inherited, suggesting the possibilite of future PGD for such traits. ${ }^{35}$ PGD is available at most infertiliy cliniques, its reported cost is about $1,000 \$$.

These techniques are already in use to eliminate embryos with serious genetic disorders. In my view, it is likely that they are also going to be used for less serious disorders in the near future. It is not clear where the line should be drawn between the avoidance of a serious disease and improvement in a child's characteristics by means of genetic selection. Huntington's disease, for example, is awful, as is cystic fibrosis. But PGD is also available for myotonic dystrophy, which according to the International Myotonic Dystrophy Organization (http://www.myotonicdystrophy.org) has the following symptoms:

"The disease causes a lot of unusual problems in people with the disease. They may have trouble staying awake and have low energy levels. They may have depression. There may be hair loss or digestive problems. It is very hard to relay to people that this is a real disease and that the problems are real and not just a result of lack of motivation. In fact, lack of motivation is one of the results of the disease. "

The welfare costs of having such a disease is probably lower than that of being poor, unemployed, or uneducated. If some people are willing to eliminate embryos with a gene for such a disease, it is likely that they would also eliminate embryos with poor predicted economic success. ${ }^{36}$

As for sex screening, it may be widespread for couples whose existing children are of only one sex, or in societies with sex-biased social norms. Chu (2001) provides evidence of prenatal sex determination in China by means of ultrasound scanning followed by selective abortion. He shows that such a practice is widespread, and especially affects girls in higher order pregancies when previous children tend to be girls. ${ }^{37}$ One may speculate that the incentives for such selection are exacerbated by the existing family planning laws which heavily tax a high number of children.

\section{Objection \#3: reproductive material cannot be traded.}

Economic cloning depends on the trade of reproductive material. One may think that it will not be openly traded, and/or that it will be prohibited. As a matter of fact, a market for reproductive material already exists in the United States. "Donors" are compensated, and there is evidence that their compensation depends on their characteristics.

Ideally, these rewards should give us an idea of how much society is willing to pay for some characteristics that, rightly or wrongly, it believes to be genetically heritable. Unfortunately, it is difficult to have systematic data on these prices. Assisted reproduction cliniques do not quote them publicly for fear of being charged with discrimination. Most of them deny practicing different prices on the basis of perceived donor quality. However, even if this is true at the establishment level, it does not preclude individual characteristics from being correlated with price at the economy level. Some establishments may offer a high price and attract the most desired donors, and others may specialize in lower segments of the market.

\footnotetext{
${ }^{35}$ Source: Science Daily Magazine, 14/01/2002 http://www.sciencedaily.com/releases/2002/01/020110074124.htm

${ }^{36}$ In particular, Clark and Oswald (1994) find a lower reported level of happiness in the unemployed.
${ }^{37}$ Theoretical implications of endogenous sex choice are discussed in Edlund (1999).
} 
Thus in order to get empirical evidence on that market, we resort to two sources: (i) case studies and anecdotal evidence, and (ii) classified advertisements on the internet, coming from independent donors and surrogates. In both cases, one should bear in mind some methodological caveats. First, these sources typically give us bid and ask prices, rather than transaction prices. Thus we may conceive that the equilibrium premium for a high IQ is zero, yet observe that donors with a high IQ attempt to get an above-market price, and fail to observe that no transaction took place or that the transaction did take place at the equilibrium price. Second, in the vast majority of cases prices are not quoted, and there may be a selfselection issue associated with price quoting. Characteristics can be misreported; for example IQ tests can be forged, while the color of hair and eyes can be artificial. Finally, as can be inferred from classifieds, many donors are not motivated by money, but by compassion, religious feelings, or sheer enthusiasm about spreading one's genes.

Keeping these caveats in mind, let us now discuss this evidence.

Egg donors: The most striking piece of evidence regarding willingness to pay for donor characteristics is an anectode reported in the Press. According to Anderlik (1999), there was an ad circulated at top universities "soliciting eggs from a 5-foot-10, athletic woman with a score of at least 1400 on her SATs and a clean family medical history (...). The incentive was $\$ 50,000$. According to an article in the New York Times, the ad generated over 200 responses (an earlier ad that failed to name a price brought in only six)." Similar figures for egg donors with 'desirable' characteristics are reported by the American Society for Reproductive Medicine (2000), which compares it with an average price of 2,500 \$.

An egg donor programme described over the internet ${ }^{38}$ is split in two categories: A normal one, offering fees of about \$3500-4500, and an "exceptional" donor programme, reserved for women with an SAT greater than 1150, an ACT greater than 20, or an IQ greater than 125 . It is explicitly said that women in this category get higher fees, but not by how much. Many other programmes do not quote any price, but mention the possibility for the 'Intended Parents' to ask the prospective donor to take an IQ test. Similar statements about the existence of an IQ premium are found in another programme. ${ }^{39}$

Sperm donors: A web advertisement for an expensive sperm donation (500 \$) mentions size, hair color, weight, an "athletic build", sports and scholarly achievements, IQ, desirable personality traits, longevity of ascendants, mother's and father's IQ, career achievements, ancestors' geographical origins, and the existence of "leaders" and top achievers among ancestors.

A reprogenetics clinic found on the internet ${ }^{40}$ separates its sperm donors in three categories:

1. A "discount" category, made of donors about whom not much is known. Each donation in this category is priced at $\$ 135$.

2. A "normal" category, which has the largest number of donors, and where much more information is provided. The corresponding price is $\$ 195$.

\footnotetext{
${ }^{38}$ http://ovatherainbow.homestead.com/eggdonor.html

${ }^{39}$ http://www.baby-miracles.com/EDFinancial.html

${ }^{40}$ http://www.fairfaxcryobank.com/
} 
3. A "doctoral" category, "comprised of donors who are in the process of earning, or have completed a Doctorate degree, these individuals include: medical, dental, chiropractic, law (juris doctorate), veterinary, optometry, pharmacy, and Ph.D. students and graduates." The price in this category is $\$ 240$.

Note that sperm donation is much cheaper than egg donation, and that the premium for "desirable" sperm is much lower than for desirable eggs. This is quite logical since sperm is reproducible at a very low cost (making male contribution to DNA quite similar to a non rival good such as knowledge); while the best donors tend to drive other donors from the market, they don't get much of a rent because of the low replication cost of their sperm. ${ }^{41}$

Internet classifieds: On the Internet can be found several databases of donors. Academic achievements, proficiency and IQ tests are frequently cited, but explicit mention of the fee is less frequent. Nevertheless, in order to go further in our analysis of the pricing of individual characteristics for egg donors, we have collected a database of 49 advertisements over the internet where price is quoted explicitly, along with some donor characteristics. Education is frequently reported, and so are test scores, but which test is reported differs across observations. SAT and GPA are most often reported, while explicit IQ scores are very rarely reported. In order to avoid reducing the number of observations by too much, we have constructed the following variables capturing intellectual achievements:

ID is a dummy equal to 1 if some test score is reported, and equal to 0 if not. DEG is a variable equal to zero for those who report high school education, or who do not report their education, to one for those who report college education, and to two for those who report some graduate education. Thus, the identifying assumption being made is that nonreporters fare poorly on these grounds. This is plausible if reporting a good score is associated with a higher price, since there is then an economic incentive to report a good score, but not a bad score.

Then we have regressed the price being asked on a set of physical characteristics as well as intellectual ones. Results are reported in the following table.

$\begin{array}{lllll}\text { Variable } & (1) & (2) & (3) & (4) \\ \text { AGE } & & & & \\ \text { SIZE } & -148.5 & & & \\ \text { WEIGHT } & -19734 * * & -18894^{* *} & -12450 & \\ \text { EYE } & -68.05^{* *} & -64.33^{*} & -35.77 & \\ \text { HAIR } & -1078.96^{* *} & & & \\ \text { DEG } & 1339.17 & & 2213.6 * * * & 1262^{* *} \\ \text { ID } & & & 162.26 & \end{array}$

\footnotetext{
${ }^{41}$ Rents are not totally eliminated, though, since donors of various education levels coexist, and the most desired donors get a premium. This is in part due to the fact that regulation puts a cap on the number of contributions from the same donor, in order to prevent future consanguinity problems; this generates artificial rents for the most desirable donors. Note also that free sperm donors are not infrequently found.
} 


\begin{tabular}{llcccc}
\hline Obs. & 41 & 43 & 43 & 18 & 18 \\
R2 & 0.27 & 0.2 & 0.35 & 0.13 & 0.31 \\
\hline
\end{tabular}
$* * *=5 \%$.

Table 1--Determinants of egg retrieval fee. Significance levels: $*=15 \% ; * *=10 \%$

The most significant determinant of price is education. An extra step in education increases the fee for an egg retrieval by about $2000 \$ .^{42}$ Furthermore education is more significant than physical traits. ${ }^{43}$ Finally, SAT scores seem to affect retrieval fee positively, by about 5 \$ per point, although this is insignificant when education is controlled for.

Even though heritability of physical traits is much more firmly established than for intellectual traits, egg buyers are willing to pay a significant premium for the genes of highly educated donors. ${ }^{44}$

Note that when human cloning becomes a mature technology, the scarcity rent is likely to disappear, as the most desirable genotypes can be cloned without limits. This is what is predicted by the above theoretical analysis, and what is largely observed in the market for sperm donors.

\section{Objection \#4: People will not want to be cloned}

One may think that people will strongly resist the idea of allowing for an identical copy of themselves. Here, several comments are in order.

First, the long-run effects of cloning on the distribution of abilities do not depend on how many people are cloned, they only depend on the fact that some people are willing to clone themselves. If only the parental motive prevails, a reduction in the number of people who clone themselves reduces the speed of convergence to the long-run equilibrium, but does not change that equilibrium. If only economic cloning prevails, the number of people willing to be cloned is irrelevant, what matters is the supply of surrogates.

Second, under economic cloning one does not even need to know that a clone has been made. One just has to agree to sell some cells to the investor; the existence of the clone need not impose any externality on the model. themselves. $^{45}$

Third, according to a 1997 poll, about $6 \%$ of the people are willing to clone

\footnotetext{
${ }^{42}$ We have also run a regression excluding observations for which DEG was equal to zero. This allows to limit oneself to cases where education was actually reported. The estimated coefficient is significant at the $10 \%$ level, and is equal to 3000 , implying that graduate studies increase the retrieval fee by $3000 \$$ compared to college studies. This suggests some convexity in the retrieval fee schedule as one moves up the ability distribution, lending plausibility to the very high prices quoted for top students at Ivy League schools.

${ }^{43}$ Of these, only size and weight are significant. An extra pound reduces the donor's income per retrieval by 68 $\$$, while an extra centimeter reduces it by almost $200 \$$.

${ }^{44}$ Some back-of-the envelope calculations can be made to estimate the rent to 'desirable' characteristics. Seibel and Kissling (1993) have estimated the opportunity cost of time for egg donors to 56 hours. At an average hourly wage of about $15 \$$, this yields an opportunity cost equal to $56 \times 15=840 \$$. The difference between that and quoted prices reflect the pains and risks associated with egg retrieval, plus a scarcity rent accruing to desirable donor characteristics. For retrieval fees above $10,000 \$$, this rent is likely to be quite large.
}

\footnotetext{
${ }^{45}$ See "Clone the clowns", The Economist, March 11997.
} 


\section{Objection \#5: Ability is not genetically determined}

The empirical relevance of our predictions clearly depends on the extent to which earnings ability is genetically transmitted. The issue is far from settled empirically. ${ }^{46}$ Surely, a fair share of the variance of earnings is acquired. For example, Ashenfelter and Krueger (1994), using a sample of identical twins, find returns to education as high as 12-16\%. This does not mean, however, that genes do not matter. Some evidence suggests that ability test scores are more correlated between twins raised apart than between non-twins reared together (See Bouchard and McGue (1981)) ${ }^{47}$.

Our reading of the evidence is as follows:

Psychometric studies often find a substantial degree of heritability in test scores, often by looking at identical twins. ${ }^{48}$

Economic studies look at income, and find little heritability, as in the above mentioned Ashenfelter and Krueger paper, or in earlier papers by Becker and Tomes $(1979,1986)$, who find a large level of intergenerational social mobility.

This evidence suggests that at least in the present situation, there is little value in cloning top earners. This seems partly due to the fact that there does not seem to be a large correlation between test scores and income. ${ }^{49}$ However, two caveats apply. First, heritability of top incomes, which is what matters for the incentive to clone, may differ from average heritability across the distribution of income. Second, heritability of income is itself endogenous and depends on technology. An individual supplies a vector of characteristics to the labor market, some of them are acquired (such as having a good network of connections or knowing where to locate valuable information), others at least partly innate (such as having a good memory or reacting quickly). His salary depends on the vector of implicit prices of each characteristic, which depends on technology $y^{50}$ and may thus vary with time. Consequently, the extent to which earnings potential is heritable is likely to be affected by technical change. It is plausible that in recent decades acquired characteristics have become more important. However, nothing precludes that this trend be reversed in the future. ${ }^{51}$

More recent evidence provided by geneticists and neuroscientists lends substantial support to the view that intelligence is heritable. Geneticists have succeeded in producing transgenic mice with an enhanced memory and better learning scores (Tang et al. (1999), Tsien (2000)). This suggests that these intellectual abilities are at least partly genetically determined. In a recent contribution, Thompson et al. (2001) find strong genetic influences on brain structure by looking at identical twins, and that these genetically determined differences in brain structure are strongly correlated with IQ. ${ }^{52}$

\footnotetext{
${ }^{46}$ Cf. the heated "Bell curve" debate in the 1990s. (Herrnstein and Murray, 1995; Devlin et al. 1997; Cawley et al. 1996; Ashenfelter and Rouse (1998)).

${ }^{47}$ Furthermore, heritable physical traits such as weight and size affect earnings (See Blanchflower and Sargent (1994), Harper (2000), and Biddle and Hamermesh (1994)).

${ }^{48}$ See in particular Plomin, R. \& Loehlin (1989);. McClearn, G.E. et al. (1997).

49 In Saint-Paul (2002), I argue that measured general ability scores may have little relation to income because the labor market allows people to specialize according to their comparative advantage, thus running against natural selection which would tend to keep only people with the highest general ability.

${ }^{50}$ For example, if glasses did not exist, being myopic would surely be severely penalized in the labor market.

51 Conceivably, new information technology such as the Internet could reduce the value of knowing how to locate information. See Hassler and Rodriguez Mora (2000) for a model where the relative importance of intelligence vs. social background depends on the economic environment.
}

\footnotetext{
52 "We found that brain structure is under significant genetic control, in a broad anatomical region that includes frontal and language-related cortices. The quantity of frontal gray matter, in particular, was most similar in
} 


\section{Objection \#6: Cloning will not be a profitable investment}

One may object to the model of cloning as a financial investment outlined above on the basis that the cost of raising a child is too high, and that the benefits are too remote for the investment to be worth being implemented. However, we can point out that there exists other areas where the payoff from investment take quite a long time, such as pharmaceutical research, for example. Furthermore, our key point is that only individuals with a very high earnings ability will be cloned.

Back-of-the-envelope calculations suggest that even a moderate rate of appropriability may make the cloning of top-earners a profitable investment. For example, with an interest rate of $2 \%$, a sunk cost of cloning of 50,000 \$, and a child-rearing cost of 10,000 \$ per year during 20 years, the total cost of the investment in PDV is equal to some $220,000 \$$. If on average one can extract $12,000 \$$ per year from the clone during the following 40 years, then this is worth the investment. With earnings of say 1,200,000 \$, a "royalty" of $1 \%$ is enough for cloning the individual to be profitable. Of course one may want to invest more in the child in order to enhance his/her human capital. With a yearly investment of 20,000 $\$$ one needs to extract 21,000 \$ per year during 40 years, which is again a few percentage points for a million-dollar earner. To be fair, however, at present it is quite unclear whether cloning a million-dollar earner would yield a million-dollar earner in expectations. Cloning is unlikely to be profitable if it yields individuals whose earnings are in the 40,000-100,000 \$ range. Cloning profitability in the future will clearly depend on how income distribution will evolve, which itself depends on technology. 'Globalization' will clearly make cloning more likely by allowing investors to locate the best genotypes worldwide, the cheapest surrogates, and the most cost-effective and adequate rearing environments.

\section{Objection \#7: Why don't we already observe a similar market for sexual reproduction?}

A relevant question is: why don't we observe, even in the absence of cloning, a market for sexually produced human beings? The answer is that this is not ruled out a priori, but the incentives for such a market to arise are weaker than in the case of cloning. There are several types of reasons for that.

First, the fact that reproducers are selected at the bottom of the ability distribution inevitably reduces the average ability of the offspring, and thus the income that can be extracted from it. ${ }^{53}$

That is not the end of the story, however. In the current state of technology, two topability parents could produce an offspring using IVF and implant it into the womb of a low ability surrogate mother. ${ }^{54}$ If the offspring were of top ability, this would not be different from cloning from an economic point of view. The preceding analysis can then be viewed as an analysis of the economic consequences of advanced reproductive techniques rather than cloning per se. However, there are again some reasons to believe that this is less likely to arise than cloning. First, some appropriability techniques such as genome ownership are less

individuals who were genetically alike; intriguingly, these individual differences in brain structure were tightly linked with individual differences in IQ. The resulting genetic brain maps reveal a strong relationship between genes, brain structure, and behavior, suggesting that highly heritable aspects of brain structure may also play a fundamental role in determining individual differences in cognition." Thompson et al. (2001).

\footnotetext{
${ }^{53}$ If a child's ability is the average of his two parents, then we get an offspring's ability equal to $(a+a *) / 2$, with $a$ low, instead of $a^{*}$ in the case of cloning.

${ }^{54}$ It is called "gestational surrogacy", as opposed to "traditional surrogacy".
} 
feasible than in the case of cloning since the offspring's genome will be unique and not identical to either parent's. Second, each parent will ex-post compete with the other in order to extract rents from the offspring, which may again reduce appropriability. Third, two top ability parents may not produce a top ability offspring, as ability results from a set of unique combinations of genes that will be broken in the course of sexual reproduction. Fourth, even though the female partner does not have to act as a gestational mother, she has to provide eggs, which is costly and dangerous. And the number of offsprings that can be produced is limited by the number of eggs that can be obtained from top ability females. This is likely to reduce the scale of such a market and to hamper its viability if there are setup costs. This is in sharp contrast to the market for cloning were the number of top ability agents willing to participate is not a limiting factor.

In short, it may well be that neither cloning nor sexual reproduction "for profit" are likely outcomes. But the former is more likely than the latter, and there exists economic environments for which the former would arise, but not the latter.

\section{Objection \#8: Markets will poorly understand genes and not be able to price them.}

Our understanding of genetic determinants of behaviour is making considerable progress, and the economic value of genetic characteristics is well understood and priced by the market in the case of animals.

The economic value of specific traits in dairy bulls is well established by hedonic studies ${ }^{55}$. Dhuyvetter et al. (1996) are able to estimate a significant effect on price of a variety of bull genetic characteristics, including race, conformation, muscle and color. Furthermore, they do find a so-called "superstar" or "winner-takes-all" effect in that the most valuable bulls sold at a price premium exceeding the estimated marginal contribution of their characteristics. ${ }^{56}$ Such premia probably reflect the fact that more of these bull's offsprings are likely to be used as inseminators, implying that the most valuables genes from an economic viewpoint tend to crowd out other genes. ${ }^{57}$

This crowding out phenomenon raises concerns about long-run biodiversity. Such concerns are empirically documented in Drucker et al. (2001). They report an erosion of domestic animal genetic resources due to selection and overbreeding, especially in developed areas such as Europe. Thus, $37 \%$ of recorded breeds are at extinction risk in Europe, and $28.9 \%$ in North America, against $6.8 \%$ in Africa and $4.0 \%$ in South America. $60 \%$ of EU cattle is derived from a single Breed, the Holstein-Friesian one. And, in accordance to the "winner-takes-all" effects apparent in the pricing of the best bulls, "50\% of the 5000 HosteinFriesian bulls born in 1990, and evaluated by the Interbull Centre, (...) were bred by only five

\footnotetext{
${ }^{55}$ See Schroeder et al. (1992), and Richards and Jeffrey (1996), who find a significant effect of performance scores in milk and protein on the price of semen doses.

${ }^{56}$ According to these authors, "(...)some bulls brought considerably higher price than the sum of the marginal predicted values of their quality differences(contributing to nonnormal residuals). (...) The top $10 \%$ highest priced bulls had an average residual of 16 to $18 \%$, suggesting prices for these bulls were under predicted on average."

57 Similar evidence about yearlings is reported in Lansford et al. (1998). They estimate a hedonic pricing equation for yearling characteristics, and find significant premia for many components of pedigree, in particular whether the sire or dam was a champion, whether second and third dams were champions, and whether the sire has produced champions. Given the "winner-takes-all" nature of horse races, they find complementarities between performance indices on the mother's side and performance indices on the father's side. Thus, the estimated premium for a champion sire rises from $1,100 \$$ for low quality dams, to $3,300 \$$ for high quality dams.
} 
sires". The authors document greater genetic diversity, i.e. a greater frequency of rare alleles, in less developed countries, as a result of less intensive breeding.

Selection possibilities have been recently enhanced by the availability of advanced reproductive techniques.

In 1998, transgenic pigs have been engineered, with a leaner meat than a normal pig. According to Weaver (1998), such pigs are worth $6 \$$ more than normal pigs, as there is less waste. $6 \$$ per pig sounds like a small number, but if multiplied by the number of pigs being slaughtered in a given year, it makes it worthwhile to invest in such an innovation, provided it is then widely adopted.

Herman is a transgenic bull who has been endowed with a human gene for producing lactoferrin, a protein which serves the purpose of enriching milk with iron, which is essential for infant growth but absent from regular cow milk. According to the USDA (1994), "This scientific advancement could have far-reaching effects for children in developing nations". ${ }^{58}$

According to the New Scientist, in October 2000, a clone of Mandy, a prize dairy cow, was auctioned to farmers in Madison, Wisconsin. Its price reached $\$ 82,000$, seven times the price of Mandy's normal calves. This sale actually took place before the clone was produced.

In the same vein is the "Missiplicity project", described at http://www.missyplicity.com/. This project aims at cloning a dog called missy. One of its stated goals is to help clone dogs of exceptional value, such as "assistance dogs for people with disabilities, and search-and-rescue dogs." The authors add: "A high percentage of dogs in service training fail to complete their programs. While these are generally fine dogs by normal standards, they lack the specific combination of intelligence, sensitivity and temperament required in a good service dog. Identifying and cloning the most effective of the current service dogs will eliminate some of the variables associated with developing these special animals."

Now, what about humans? The above evidence on gamete prices suggests that donors' physical and intellectual characteristics do have an effect on their price. Clearly, though, one has not identified specific genes for intelligence, being a good astronaut or having excellent social-skills. The day this is done, one will be able to 'customize' humans just as one is starting to do so for animals, as in the case of Herman. Meanwhile, cloning allows to replicate a favorable combination of genes even though one does not understand which genes really matter and why such a combination is successfull.

As the Mandy and Missy examples suggest, cloning allows investors to free-ride on nature, which, thanks to chance and sexual reproduction, sometimes produces outstanding individuals, and on the labor market, which reveals the true economic value of such individuals. Thus it allows to replicate a combination of genes which causes economic success, even though such combination may be complex, rare and poorly understood.

\section{Objection \#9: cloning will be banned}

This is not the place to discuss the moral aspects of cloning; the reader can refer to the NBAC report (1997). Let us point out, though, that moral values evolve, and are probably not independent of economic forces. Is the fact that divorce is more morally acceptable than 100

\footnotetext{
58 Source: http://www.accessexcellence.org/AB/BA/Herman\the \BBll.html. One could give many more examples. In January 02, transgenic pigs were produced with spinach genes, etc. A compilation of brief scientific reports on advances in genetic technologies can be found at http://www.genecrc.org/site/hi/hilarch.cfm?code=geneticsnews
} 
years ago independent of the fact that technical change has considerably increased a woman's return to labor market participation relative to homework?

From an economic point of view, cloning should be deterred if it exerts some externalities. Even then, one could argue that a tax or quota is more appropriate than prohibition.

A first concern is about cloning raising inequality. This is hard to justify since one is not talking about having more poor, or about the poor getting poorer, but about having more rich people. That is, shouldn't reasonable social welfare functions be increasing if the distribution of income improves in a first-order sense? Furthermore, inequality need not increase. As we have seen, under the ability invariance assumption, society is perfectly egalitarian in the long run. And, in the short-run, cloning benefits poor women who increase their income by specializing in surrogacy. In fact, surrogacy fees currently are currently about 20,000 to $30,000 \$$, which is above median U.S. annual income.

Another type of externality may have to do with social norms. By banalizing high performance, cloning of top ability people may raise social norms and harm non cloned people by reducing their income and labor market prospects. Indeed, one does not need social norms: this may be mediated by technology and the labor market. ${ }^{59}$ This in turn may contribute to displacement of sexual reproduction in the long run. The problem with this argument is that it may also be used to repress the use of any technology which leads to improved ability, such as education, the use of computers, etc. Admittedly, however, public policy may intervene to help the least educated or those who don't use computers to cope with the rising social norm; this is clearly impossible when one deals with a social norm of being genetically enhanced.

Finally, by reducing diversity, cloning may increase systemic risk in human populations. By selecting the same genes, cloning may lead to an impoverishment of the population's gene pool. This can have an adverse effect if the population faces environmental shocks. There are several objections to this argument, however. First, why should a population care about its future survival as a whole, rather than simply the sum of the survival probabilities of all its members? Second, an option for restoring genetic diversity in case of future needs can be maintained by means of a genetic bank of frozen reproductive material.

This discussion is normative: it sorts out some of the potential social costs and benefits of cloning. What about positive aspects? Do people have an interest in allowing cloning? In fact, they do, because high ability clones raise the tax base in relation to GDP. As shown in the Appendix, where we consider a model where people vote on the degree of appropriability of a clone's income, voters are willing to allow a certain level of appropriability in order to enjoy the extra public expenditures allowed by the presence of high ability clones.

\section{Conclusion}

This paper was motivated by the author's view that human cloning is inevitable, and will take place rather soon. It has identified various economic forces for human cloning: assisted reproduction, child enhancement, and investment. It is not clear whether these forces are strong enough for the corresponding phenomena to actually arise. But we have analyzed their implications for the long-run distribution of ability, and provided evidence that these forces are already at work to some extent. And it is likely that cloning as a means of assisted reproduction is around the corner.

\footnotetext{
59 While this runs contrary to standard economic assumptions which assume that high skill workers are complements with low skill ones, there exists a body of recent theoretical work where an increase in the supply of skilled workers reduces the labor market prospects of the unskilled. See Saint-Paul (1998) and Acemoglu (1999).
} 
A difficult question is: what can and should policy do? We have only tackled it from the economist's viewpoint, identifying some externalities. As in the case of other externalities such as pollution, taxation rather than prohibition is likely to be the appropriate response. But this clearly ignores ethical and philosophical considerations, which have recently prevailed in the decisions of most western countries (especially Catholic ones) to ban human cloning.

It is not clear whether such legal prohibition can resist strong economic incentives. While lawyers say yes, economists say no. And facts agree with them. Drugs are prohibited and yet widely consumed among Western youth, and even advertised in the lyrics of rock bands. Abortion was prohibited not so long ago and prohibition eventually gave in, while values evolved so as to make it more acceptable. Alcohol prohibition in the 1920's was a major failure, while excess taxation of tobacco recently gave rise to smuggling. As for cloning, it can be performed in countries where it is not banned-transportation costs are minor relative to other cloning costs and to its benefits. Or it can simply be disguised as traditional IVF. Prohibition will be effective only if the private incentives to clone are not too high.

\section{REFERENCES}

American Society for Reproductive Medicine (2000) "Financial incentives in recruitment of oocytes donors", Fertility and Sterility, 74, 2, 216-220

Anderlik, Mary (1999) " Market Making Inroads in Organ Transplantation, Assisted Reproduction", University of Houston, http://www.law.uh.edu/healthlawperspectives/Bioethics/990526Market.html

Ashenfelter, Orley, and Allan Krueger (1994), "Estimates of the return to schooling from a new sample of twins", American Economic Review, 84, 5, December

Ashenfelter, Orley, and Cecilia Rouse (1998), "Schooling, Intelligence, and Income in America: Cracks in the Bell curve", Princeton University Industrial Relations Section Working Paper \#407, November

Becker, Gary S. and Nigel Tomes, (1979) "An Equilibrium Theory of the Distribution of Income and Intergenerational Mobility" Journal of Political Economy; 87(6), pages 115389.

Becker, Gary and Nigel Tomes (1986), "Human Capital and the Rise and Fall of Families", Journal of Labor Economics; 4(3), Part 2 July 1986, pages S1-39.

Bergstrom, Theodore (1994), "On the economics of polygyny", UCSB Working Paper

Bergström, Theodore (1996), "Economics in a family way", Journal of Economic Literature, 1996

Biddle, J. and D. Hamermesh (1994), "Beauty and the labor market", American Economic Review 
Blanchflower, David and James Sargent (1994), "Obesity and stature in adolescence and earnings in young adulthood", Archives of Pediatrics and Adolescent Medicine, 148, 681687

Borgerhoff Mulder, Monique (1998), Kipsigis bridewealth payments", in Betzig, L., Borgerhoff Mulder, M. and P. Turke, eds, Human reproductive behaviour: A Darwinian Perspective, Cambridge: Cambridge U. Press, 65-81

Borgerhoff Mulder, Monique (1995), "Bridewealth and its correlates", Current Anthropology, 36,3, 573--603

Bouchard, T.J. and M. McGue (1981), "Familial studies of intelligence: A review", Science, 212, 4498, 1055-1059

Cameron, Samuel and Alan Collins (1999), "Looks unimportant? A demand function for male attractiveness by female personal advertisers", Applied Economics Letters, 6, 381-84

Case, Anne, I Fen Li, and Sara McLanahan (2000), "How hungry is the selfish gene?", Economic Journal 110(466), 781-804

Cawley, John, K. Conneely, James Heckman, and Edward Vytlacil (1996), 'Measuring the effects of cognitive ability", NBER Working paper 5645, July

Chester, Ronald (1997), "To be,be,be...Not Just to Be: Legal and Social Implications of Cloning for Human Reproduction", Florida Law Review, 49, 304-337

Christie, Bryan and John von Radowitz, (1997) "Artificial Human Womb 'in Ten Years'", The Scotsman, July 18, 1997

Chu, Junhong (2001), "Prenatal sex determination and sex-selective abortion in rural central China", Population and Development Review, 27(2), 259-81

Clark, Andrew and Andrew Oswald (1994), "Unhappiness and Unemployment", Economic Journal, 104, 648-59

Dawkins, R.,(1990) The Selfish Gene. Oxford: Oxford U. Press

Devlin, Bernie, Stephen Fienburg, Daniel Resnick and Kathryn Roeder (1997), Intelligence, Genes, and Success: Scientists Respond to the Bell Curve.

Dhuyvetter, K.C., T.C. Schroeder; D. Simms, R.P. Bolze, and J. Geske (1996), "Determinants of purebred beef bull price differentials" Journal of Agricultural and Resource Economics 21(2) 396-410

Drucker, A.G., V. Gomez and S. Anderson (2001), "The economic valuation of farm animal genetic resources: a survey of avilable methods", Ecological Economics, 2001, 1-18\}

Edlund, Lena (1999), "Son preference, sex ratios, and marriage patterns", Journal of Political Economy, 107(6), 1275-1304 
Green, Ronald M. (1999), "I, Clone", Scientific American, September.

Hadfield, Peter "Japanese Pioneers Raise Kid in Rubber Womb" (1992), The New Scientist, April 25.

Harper, B. (2000), "Beauty, stature and the labour market: a British cohort study", Oxford Bulletin of Economics and Statistics, 62(0) 771-800

Hassler, John, and José Vicente Rodriguez Mora (2000), "Intelligence, Mobility, and Growth", American Economic Review

Herrnstein, Richard and Charles Murray (1995), The Bell Curve: Intelligence and Class Structure in American Life

Kuwabara, Yoshinori (1992) "Experimental Perinatology---Development of Extrauterine Fetal Incubation System", Nippon Sanka Fujinka Gakkai Zasshi, 982

Lansford, N., D.W. Freeman; D.R. Topliff; and O. Walker (1998), "Hedonic Pricing of Race-Bred yearling Quarter Horses Produced by Quarter Horses Sires and Dams", Journal of Agribusiness, Fall, 169-185

McClearn, G.E. et al. (1997) "Substantial genetic influence on cognitive abilities in twins 8 or more years old" Science 276(5318):1560-3

Murray, J.E. (2000), "Marital protection and marital selection: evidence from a historical-prospective sample of American men", Demography, 37(4),511-521

Nakosteen, Robert A. and M.A. Zimmer (1997), "Men, money, and marriage: Are high earners more prone than low earners to marry?", Social Science Quarterly, 78(1), 66-82

National Bioethics Advisory Commission (1997), Cloning Human Beings

Orentlicher, D. (1999), "Cloning and the preservation of family integrity", Louisiana Law Review, 59, 1019-1040

Plomin, R. \& Loehlin, J.C. (1989) Direct and indirect IQ heritability estimates: a puzzle. Behav. Genet. 19, 3:331-42

Posner, Richard A. (1989) "The Ethics and Economics of Enforcing Contracts of Surrogate Motherhood", Journal of Contemporary Health Law and Policy

Posner, Eric A. and Richard A. Posner (1998) "The demand for human cloning" in Martha C. Nussbaum and Cass R. Sunstein, eds., Clones and clones: Facts and fantasies about human cloning. Reprinted and updated in Hofstra Law Review, 27, 3, 1999, 579-608

Richards, T.J. and S.R. Jeffrey (1996), "Establishes indices of genetic merit using hedonic pricing: an application to dairy bulls in Alberta", mimeo, U. of Alberta. 
Robertson, J.A. (1997), "A Ban on Cloning and Cloning Research is Unjustified", Testimony presented to the National Bioethics Advisory Commission, March 1997. -- (1998), "Liberty, Identity, and Human Cloning", Texas Law Review 76 (1999), "Two models of human cloning", Hofstra Law Review 27, 3, $609-638$

Saint-Paul G. (2000), "The economics of human cloning"; working paper, CEPR and IZA

forthcoming.

(2002), "On market forces and human evolution", working paper,

Schroeder, T.C., J.A. Espinosa, and B.K. Goodwin (1992), "The value of genetic traits in purebred dairy bull services", Review of Agricultural Economics 14: 314-22

Siebel, MM and A. Kiessling (1993), "Compensating egg donors: equal pay for equal time?", New England Journal of Medicine, 328, 737

Tang, Y. P.; Shimizu, E.; Dube, G.; Rampon, C.; Zhuo, M.; Liu, G.; and Tsien, J. Z. (1999). "Genetic enhancement of learning and memory in mice" Nature 401:63-69.

Thompson, P.M., Cannon, T.D., Narr, K.L., van Erp, T.G.M., Poutanen, V.P., Huttunen, M., Lönnqvist, J., Standertskjold-Nordenstam, C.G., Kaprio, J., Khaledy, M., Dail, R., Zoumalan, C.I., Toga, A.W. (2001). "Genetic Influences on Brain Structure", Nature Neuroscience, 4(12):1253-1258

Tsien, J. Z. (2000). Building a brainier mouse. Scientific American. April issue. Vol. 282, p62-68.

U.S. Census Bureau (1997), Current Population Report: Fertility of American Women, P20-499, October.

Watson, James D. (1971), "Moving toward the clonal man", The Atlantic Monthly, 227(5), \}May, 50-53.

Weaver, T. "New transgenic pigs with lean pork potential", USDA, 1998, http://www.ars.usda.gov/is/pr/1998/980218.htm

Wilson, E.O. (1974), Sociobiology: The New Synthesis. Cambridge MA: Harvard U. Press 
APPENDIX

1. A formal model of parental cloning

Let $a_{1}, a_{2}$ be the skills of the parents, with $a_{1}>a_{2}$. Let $a$ be the child's ability, and assume that the utility obtained by a parent $i$ from having a child is:

$U_{i}=\theta a=\theta a_{i}$ if the child is a clone of the parent

$U_{i}=\frac{1}{2} a=\frac{1}{4}\left(a_{1}+a_{2}\right)$ if the child is sexually produced

$U_{i}=\gamma a=\gamma a_{-i}$ if the child is a clone of the other party.

We shall assume $\gamma<\theta$ and $\gamma<1 / 2$. $\theta$ can be either greater or smaller than 0.5. Thus we do not rule out that people actually love their sexually produced offspring better than their clone, despite sharing more genes with the clone. The sociobiological view which relates altruism to the coefficient of kinship, i.e. the number of shared genes, corresponds to the case where $\theta=1$ and $\gamma=0$. Note that ability enters multiplicatively with the altruism coefficient. This is reasonable; there is no reason to gain from an increase in ability in somebody whom one does not care about. However, little would be changed under an additive formulation. ${ }^{1}$

We assume that the reproductive decision is made by maximizing the joint surplus of the two parents, i.e. $U_{1}+U_{2}$. This joint surplus is equal to

$(\theta+\gamma) a_{1}$ if party 1 is cloned;

$\left(\left(a_{1}+a_{2}\right) / 2\right)$ if the child is naturally produced; and

$(\theta+\gamma) a_{2}$ if party 2 is cloned.

Clearly, party 2 will never be cloned. On the other hand, party 1 will be cloned if and only if:

$$
(\theta+\gamma) a_{1}>\left(\left(a_{1}+a_{2}\right) / 2\right)
$$

which is equivalent to

$$
\frac{a_{1}}{a_{2}}>\frac{1}{2(\theta+\gamma)-1}
$$

This formula has some interesting properties.

The left hand side is the ratio between the two party's abilities, a measure of intra-household inequality. Thus cloning is more likely to take place, the more ill-assorted is the couple. The more assortative mating prevails in a given society, the lower the number of clones being produced by this society.

\footnotetext{
${ }^{1}$ For example, (1) below would be replaced by $a_{1}-a_{2}>1-\theta-\gamma$, with similar properties.
} 
The RHS is lower, the greater $\theta$ and $\gamma$. If $\theta+\gamma=1$, which is the case under the 'sociobiological' hypothesis, then cloning always takes place. In such a case, the increment in one parent's altruism exactly compensates for the reduction in the other parents' altruism, so that cloning is always preferred as it yields higher ability children. In the other limit case where $\gamma=0$ and $\theta=1 / 2$, i.e. if one derives no utility at all from raising a genetically unrelated child, and if one gets zero extra utility from raising a clone rather than a natural child of similar ability, then cloning never takes place, as the reduction in the household's overall altruism toward the child always dominates the effect from greater child quality. Finally, note that as long as $\theta+\gamma>1 / 2$, cloning will occur for large enough differences between the two parties' ability levels. This may well occur for $\theta<1 / 2$, i.e. if one feels more altruism for one's sexually produced children than for one's clones. The possibility of choosing the offspring's ability compensates for the reduction in altruism.

2. Long-run consequences: the evolution of the ability distribution under parental cloning

Consider the following simple case. We assume that $\theta+\gamma=1$, but that only fraction $\psi$ of couples are willing to produce clones. Mating is random and the birth rate is the same for all couples. Finally, the distribution of ability $a$ among sexually produced offsprings is the same as among parents. ${ }^{2} \mathrm{We}$ will refer to this property as 'Ability Invariance'. Let us assume that ability is distributed over $[0, \bar{a}]$, and denote by $f_{t}(a)$ the ability distribution of generation $t$, as well as by $F_{t}(a)$ the cumulative, with $F_{t}^{\prime}()=.f_{t}($.$) . Then the$ evolution of $f$ is given by:

$$
f_{t+1}(a)=(1-\psi) f_{t}(a)+2 \psi f_{t}(a) F_{t}(a)
$$

The first term is the contribution of sexually produced offsprings, which reflects our assumption that the distribution of skills is left invariant by sexual reproduction. The second term is the contribution of clones. The first party will be cloned and produce an offspring of type $a$ if it is of type $a$ and mated with a second party of lower ability, which occurs with a probability density

\footnotetext{
${ }^{2}$ This will be true, for example, if a child's ability is equal to $a_{1}$ with probability $1 / 2$ and to $a_{2}$ with probability $1 / 2$.
} 
equal to $f(a) F(a)$. The coefficient 2 comes from the symmetrical case of the second party being cloned and of ability $a$.

Now, the key property of this equation is that the density of any given type $a$ increases if and only if $F_{t}(a)>1 / 2$. Therefore, this process takes mass below the median to reallocate it above the median. As illustrated on Figure 1, over time the distribution of skills is distorted in favour of more able people. Furthermore, it converges to a mass point at the highest ability type $\bar{a}$.

Hence we get the following central result discussed in the text:

Under the Ability Invariance assumption, society converges to a perfectly egalitarian world with only people of the highest ability type.

It is important to note that this result is valid regardless of the value of $\psi$. Even a tiny amount of cloning is enough to gradually eliminate low ability types from the population and to make sure that the distribution of ability converges to a mass at $\bar{a}$.

What happens if $\theta+\gamma<1$ ? In such a case, the well-assorted couples who are willing to make clones will actually prefer to make natural children. Cloning will take place only if $a_{2}<\rho a_{1}$, with $\rho=2(\theta+\gamma)-1<1$. One can then prove that the evolution equation has to be replaced with ${ }^{3}$

$$
f_{t+1}(a)=(1-\psi) f_{t}(a)+\psi f_{t}(a)\left[F_{t}(a / \rho)+F_{t}(\rho a)\right]
$$

As long as $\rho>0$ and $f($.$) has full support, the term in brackets is strictly$ increasing in $a$. Therefore, this process again converges to a mass point at the highest ability type $\bar{a}$. Similarly, one can relax the assumption of pure random matching. As long as the distribution of couples has full support in $[0, \bar{a}]^{2}$, at each generation some couples will produce clones and tilt the distribution of skills in the next generation in favor of high ability types, until one converges again to a mass point at $\bar{a}$.

\section{More details on the model of economic cloning}

Consider a simple model of overlapping generations of "agents", each living two periods. People work when young and differ in their innate ability

\footnotetext{
${ }^{3}$ To see this, assume that a couple with abilities $a_{1}$ and $a_{2}$ produces a child of ability $a_{1}$ with probability $1 / 2$ and a child of probability $a_{2}$ with probability $1 / 2$. Then among those willing to clone themselves, a density $2 f(a) F(\rho a)$ will produce clones of ability $a$, while the density of sexually produced children of ability $a$ is given by $2 \frac{1}{2} f(a)[F(a / \rho)-F(\rho a)]$. Adding the two, we get the term in brackets.
} 
$a$, which is interpreted as productivity per unit of time and distributed over $[\underline{a}, \bar{a}]$. When young they produce a fixed number $n$ of natural children, and can invest part of their income to finance their consumption when old, getting a real rate of return $r$.

Young agents have a fixed time endowment, which we normalize to one. They can either supply it to the labor market, getting an income equal to $\omega a$, or they can act as a surrogate mother, producing clones of others. ${ }^{4}$ In this case they must spend a fraction of their time $b$ per clone risen, and they are paid a price $p . p$ is the equilibrium price of a clone, or equivalently the rental rate of a womb. All wombs are equivalent, so that $p$ does not depend on the surrogate's characteristics. There is no cost of cloning other than the time of surrogate mothers. Consequently, in order to clone oneself, an individual just has to transfer $p$ to the surrogate.

Clones have exactly the same ability as their model. When old, a cloned individual can appropriate a fraction $\varphi$ of his clones' income.

Consider an individual with ability $a$. If he or she produces a clone of himself/herself, this person will earn aw next period. ${ }^{5} \mathrm{~A}$ fraction $\varphi$ of that income goes to the model. And the cost of producing the clone is $p$. Thus cloning oneself is an investment which costs $p$ and yields $\varphi a \omega$ next period. This investment is profitable if it yields a greater return than the financial market, i.e.

$$
\varphi a \omega \geq p(1+r)
$$

which is the equation derived in the text. As discussed there, it must hold with equality in equilibrium, otherwise the demand for clones would be infinite. Hence $p$ must satisfy

$$
p=\frac{\varphi \bar{a} \omega}{1+r} .
$$

This proves that only the top ability individuals will be cloned. The surrogacy decision is straightforward. An individual with ability a sacrifices $b$ units of time to bear a clone, which is profitable if and only if:

$$
p \geq b a \omega .
$$

\footnotetext{
${ }^{4}$ Thus the production function is $Y=r K+\omega L$, where $K$ denotes total capital and $L$ is the total labor input in efficiency units.

${ }^{5}$ This assume that the clone will work on the labor market rather than act as a surrogate, which is typically true.
} 
Consequently surrogates are those with an ability level lower than

$$
a^{*}=\frac{p}{b \omega}
$$

Substituting (2), we see that cloning arises in equilibrium if and only if:

$$
\frac{\underline{a}}{\bar{a}}<\frac{\varphi}{b(1+r)}
$$

4. Long-run consequences: evolution of the ability distribution under the ability invariance assumption and economic cloning

Let us again consider the ability invariance assumption. Call again $F_{t}(a)$ the c.d.f. of ability at generation $t$, and $f_{t}(a)$ its density. At each generation there are $n$ natural offsprings being produced, and given that fertility is the same for all agents, the distribution of skills among these people is the same as among their parents. Furthermore, a fraction $F_{t}\left(a^{*}\right)$ produce $1 / b$ top-ability clones each. Hence, population grows at rate $n+F_{t}\left(a^{*}\right) / b$ and at each generation there is a density of skills $f_{t}(a)$ plus a mass $M_{t}$ of top ability people such that $\int_{\underline{a}}^{\bar{a}} f_{t}(a)+M_{t}=1$, and which satisfies the following evolution equation:

$$
\begin{aligned}
& f_{t+1}(a)=\frac{n f_{t}(a)}{n+F_{t}\left(a^{*}\right) / b} \\
& M_{t+1}=\frac{n M_{t}+F_{t}\left(a^{*}\right) / b}{n+F_{t}\left(a^{*}\right) / b}
\end{aligned}
$$

It is clear that the density of non top ability people falls with time, while the mass of top ability ones goes up and converges to one. In the long run, the economy tends to a perfectly egalitarian one with only top ability people. Furthermore, if

$$
\frac{\varphi}{b(1+r)}<1
$$

i.e. if $a^{*}<\bar{a}$, then the fraction of surrogate mothers $F_{t}\left(a^{*}\right)$, and therefore the number of clones being produced vanishes relative to the size of the population. Cloning has disappeared but played a key role in moving the economy toward the egalitarian utopia.

This proves the results discussed in the text. 


\section{The Gene invariance assumption}

We now extend the previous results under the gene invariance assumption.

To express our model in terms of genetic fundamentals, we assume that the genetic code of any given individual is an n-uple $\left(g_{1}, \ldots g_{N}\right)$ where each $i=1, \ldots N$ indexes the location of the gene and each gene is drawn from a given set $G$. We assume that the distribution of genes among sexually produced offsprings is the same as among parents. We denote the distribution of genes at date $t$ by a measure $\mu_{t}$ over $G$. Ability is a function of one's genetic code, described by the following function: ${ }^{6}$

$$
a=h\left(g_{1}, \ldots, g_{N}\right)
$$

Let $S(a)=\left\{g \in G \mid \forall\left(g_{1}, \ldots g_{N}\right) \in G^{N},\left(\exists i\right.\right.$ s.t. $\left.\left.g_{i}=g \Longrightarrow h\left(g_{1}, \ldots g_{N}\right)<a\right)\right\}$. $S(a)$ is the set of genes such that if an individual has one of them, then his ability is strictly below $a$. Clearly $S(a) \subset S\left(a^{\prime}\right)$ for $a<a^{\prime}$.

We make the following assumption

$$
\mu_{0}\left(S\left(a^{*}\right)\right)>0
$$

This means that at the initial date $t=0$ there is a strictly positive measure of genes that prevent ability from being above $a^{*}$.

Proposition - Assume (H2) holds. Then in any steady state $\mu(S(\bar{a}))=0$.

PROOF - Top ability people cannot have any gene in $S(\bar{a})$. Therefore, these genes are only transmitted via sexual reproduction. This is also true for any $S(a)$ with $a<\bar{a}$. For $\mu(S(\bar{a}))$ to be strictly positive in steady state, there must not be any cloning. Otherwise the genes of top ability people would increase in frequency from a generation to the next, which would reduce $\mu(S(\bar{a}))$. On the other hand, the conservation law of genes implies that

$$
\frac{\mu_{0}\left(S\left(a^{*}\right)\right)}{\mu_{0}(S(\bar{a}))}=\frac{\mu\left(S\left(a^{*}\right)\right)}{\mu(S(\bar{a}))} .
$$

i.e., cloning affects the relative proportions between sexually transmitted and cloned genes, but not between two sexually transmitted genes.

Since (H2) holds, it must then be that $\mu\left(S\left(a^{*}\right)\right)>0$. But this implies that there is a strictly positive mass of agents willing to specialize in surrogacy.

\footnotetext{
${ }^{6}$ The preceding analysis is a special case with $N=1, G=[\underline{a}, \bar{a}], h(x) \equiv x$.
} 
This contradicts the fact that there must not be any cloning. Consequently, it must be that $\mu(S(\bar{a}))=0$. Q.E.D.

\section{Extension I: Negative ability dependence of birth rates}

To take care of such negative ability dependence, one may assume that the number of sexually produced offsprings now depends on ability, i.e. $n=$ $n(a), n^{\prime}<0$. One may also naturally assume that their ability distribution is the same as that of their parents, weighted by fertility. That is, absent cloning the density of people with abiliy $a$ among sexually produced offsprings is given by

$$
f_{t+1}(a)=\frac{n(a) f_{t}(a)}{\bar{n}}
$$

where $\bar{n}=\int_{\underline{a}}^{\bar{a}} n(a) d a$.

This implies that in any equilibrium, the density of any worker type such that $\underline{a}<a<\bar{a}$ must be falling relative to $f(\underline{a})$, since none of these people are cloned. Consequently, in any steady state, there are only two possible ability types in positive supply: $\underline{a}$ and $\bar{a}$. If (4) holds, then low ability people will devote all their working time to produce clones. Assuming again that each produces $1 / b$ clones, and calling $M_{t}$ the proportion of top ability agents, we see that $M_{t}$ evolves as

$$
M_{t+1}=\frac{n(\bar{a}) M_{t}+\left(1-M_{t}\right) / b}{n(\underline{a})\left(1-M_{t}\right)+n(\bar{a}) M_{t}+\left(1-M_{t}\right) / b}
$$

Normalizing the size of the initial cohort to one, the numerator if the total number of top ability offsprings. The denominator is the total number of offsprings. Clearly, $M$ converges to its steady state value given by

$$
\bar{M}=\frac{1 / b}{n(\underline{a})-n(\bar{a})+1 / b} .
$$

This is greater, the greater the cloning rate $1 / b$ and the smaller the fertility gap $n(\underline{a})-n(\bar{a})$. In the extreme case when there is no cloning, $b=\infty$ and only low ability people remain in the long run. If the fertility gap is zero, then we are back to the ability invariance case and only top ability people remain in the long run.

7. Extension II: Non homogeneous labor input

In the above model, there is a single homogeneous labor input, i.e. ability is unidimensional. What would happen if ability were multidimensional? Let 
us assume that people are endowded with a scalar measure of physical productivity $a \in[\underline{a}, \bar{a}]$ as well as a qualitative talent $j \in[0,1]$ which defines their occupation. For simplicity let us assume that both are perfectly heritable, and that occupations are complementary in production, so that the wage per efficiency unit of labor of occupation $j$ is a decreasing function of the total number of labor units supplied in occupation $j$ relative to other occupations:

$$
\omega_{j}=\omega\left[\frac{l_{j}}{L}\right]^{\alpha-1},
$$

where $l_{j}=\int_{j(i)=j} a(i) d i$ is total labor supply in occupation $j$, and $L=$ $\left(\int_{0}^{1} l_{j}^{\alpha} d j\right)^{1 / \alpha}$ is an index of average labor supply across sectors. ${ }^{7}$

How are the above results modified? The highest price for a clone can be obtained by cloning the most able individuals within the most paid occupation, i.e. the one in lowest relative supply. That is,

$$
p=\frac{\varphi \omega \bar{a}}{1+r} \max _{j} \omega_{j}
$$

An individual with ability $a$ in occupation $j$ would elect to work as a surrogate if and only if

$$
p>b a \omega_{j}
$$

Consequently, cloning takes place if and only if the following condition holds

$$
\frac{\underline{a}}{\bar{a}}<\frac{\varphi}{b(1+r)} \frac{\max _{j} \omega_{j}}{\min _{j} \omega_{j}}
$$

This is more likely to hold than (4), so that as long as (4) holds, cloning does take place. Furthermore, cloning top individuals of type $j$ reduces $\omega_{j}$ down to the point where it is equal to the next highest value of $\omega_{i}$, at which point both types are cloned in such proportions as to maintain $\omega_{i}$ equal to $\omega_{j}$, and so on. This process continues as long as (5) holds. But note that if (4)

\footnotetext{
${ }^{7}$ The underlying production function is $Y=r K+\omega L$, with $L$ being now this aggregate index. Note that for $\alpha=1$ one is back to the previous model.
} 
does not hold but (5) initially does, then cloning only takes place transitorily, until it has reduced the wage gap between the top and bottom occupations by enough for to (5) to be violated.

8. Public cloning: Political economy considerations

Going back to the previous model, let us assume that there is no appropriability of the clone's income, say because of constitutional impediments, but that the government may subsidize cloning by transferring a fraction $\varphi$ of the clone's income to the model. Suppose there exists a pension system which gives a constant pension to each old, by taxing the young's labor income at a rate $\tau$. The young of a given generation can then get together collectively and vote in favor of a balanced budget subsidy to cloning which ensures an appropriability level equal to $\varphi$. The market for cloning would then operate as described in the previous subsection. The young will be willing to engage in such a scheme if the gains in terms of future pensions are larger, in discounted terms, than the cost of cloning.

Cloning will generate $F\left(a^{*}\right)$ high ability clones, who will each earn $\omega \bar{a}$ and give away a fraction $\tau$ in order to finance pensions. Thus the gains are equal to

$$
\tau F\left(a^{*}\right) \frac{1}{b} \omega \bar{a}
$$

For each clone, the amount $\varphi \bar{a} \omega$ must be transferred to the clone's model, who has already dissipated it as a payment to the surrogate. Thus, the costs are equal to

$$
\varphi \bar{a} \omega F\left(a^{*}\right) \frac{1}{b}
$$

The young generation sets $\varphi$ so as to maximize costs minus benefits, or equivalently

$$
\max _{\varphi} F\left(a^{*}\right)[\tau-\varphi]
$$

subject to

$$
a^{*}=\frac{\varphi \bar{a}}{b(1+r)} .
$$

This maximization problem determines the amount of cloning chosen by this society. Just as in the preceding subsection, cloning is an investment in 
order to finance future consumption. But, here, the investment is collective, because the appropriability technology is itself collective and mediated by the pension system and the tax rate $\tau$.

The first-order condition is

$$
-F\left(a^{*}\right)+[\tau-\varphi] f\left(a^{*}\right) \frac{\bar{a}}{b(1+r)}=0
$$

This has the following properties. First, the subsidy rate $\varphi$ cannot exceed the fraction of the clone's income paid to society, $\varphi$. Second, if $\lim _{a \rightarrow \underline{a}} \frac{f(a)}{F(a)}=$ $+\infty$, then there will always be a strictly positive amount of cloning. In the simple case where $f($.$) is uniform with \underline{a}=0$, the first-order condition boils down to the simple rule:

$$
\varphi=\tau / 2
$$

Hence the young are willing to finance an appropriability level equal to half the tax rate. 